\title{
The Implementation of Mutually using Lewis and Brønsted Acidic Functionalized Carbon supported Solid Acid Catalysts derived from Palm Oil Empty Fruit Bunch for 5-Hydroxy Methylfurfural (5-HMF) Production
}

\section{Amporn Kuntinuguntanon}

Kasetsart University - Bangkhen Campus: Kasetsart University

\section{Supacharee Roddecha ( $\nabla$ fengsrro@ku.ac.th )}

Kasetsart University Faculty of Engineering https://orcid.org/0000-0001-7675-9804

\section{Supakrit Pumrod}

Kasetsart University - Bangkhen Campus: Kasetsart University

\section{Attasak Jaree}

Kasetsart University - Bangkhen Campus: Kasetsart University

\section{Amaraporn Kaewchada}

King Mongkut's Institute of Technology North Bangkok: King Mongkut's University of Technology North Bangkok

\section{Research Article}

Keywords: 5-hydroxymethylfurfural (5-HMF), palm oil empty fruit bunch (POFB), solid acid catalyst, Lewis acid catalyst, Brønsted acid catalyst

Posted Date: May 5th, 2021

DOl: https://doi.org/10.21203/rs.3.rs-442931/v1

License: (c) (i) This work is licensed under a Creative Commons Attribution 4.0 International License.

Read Full License

Version of Record: A version of this preprint was published at Waste and Biomass Valorization on August 4th, 2021. See the published version at https://doi.org/10.1007/s12649-021-01525-8. 


\section{Abstract}

This work presents the utilization of dual Lewis and BrØnsted solid acid catalysts synthesized from the acidic functionalized abundant wasted palm oil fruit bunch (POFB) derived porous carbon for a one-pot conversion of glucose to 5-HMF under a bi-phasic NMP- $\mathrm{H}_{2} \mathrm{O} / \mathrm{MIBK}$ system. The multiscale-porous POFB based carbon with an enhanced surface area $~ 1,600 \mathrm{~m}^{2} \cdot \mathrm{g}^{-1}$ was obtained at the optimized preparing condition (1:2 biochar to $\mathrm{KOH}$ mass ratio and carbonization at $850^{\circ} \mathrm{C}$ ). The impregnated $\mathrm{Al}_{2} \mathrm{O}_{3}$ and the sulfonated POFB derived carbon provided the Lewis (PC-Im1 AILA and PC-Im4AILA) and Brønsted (PCIm50BA) acid catalysts possessing total acidity up to 2.4 , and $13.0 \mathrm{mmol}^{-1}{ }^{-1}$, respectively. The optimized reaction condition parameters and the synergistic effect of mutually using both acidic catalysts were extensively investigated to achieve the most efficient 5-HMF production performance. The highest 5-HMF yield, glucose conversion, and 5-HMF selectivity of $63.9 \%, 100 \%$, and $63.9 \%$, respectively, was attained at $120^{\circ} \mathrm{C}$, for $6 \mathrm{hr}$ by employing 0.005:0.04 catalyst mass ratio of PC-Im4AILA to PC-Im50BA with addition of some $\mathrm{NaCl}, 1: 3$ and 3:1 aqueous to organic phase and NMP to $\mathrm{H}_{2} \mathrm{O}$ volume ratios, respectively. Besides, the proposed catalytic system could be recycled for 3 times with less than $20 \%$ reduction of 5 HMF production yield.

\section{Statement Of Novelty}

The important novelty of this work is the first time utilization of the agro-palm oil empty fruit bunch waste as a base to produce the high value-added solid acid catalysts that can function either as BrØnsted or Lewis acidic sources. Moreover, these proposed acid catalysts could be successfully prepared thereby a practical and affordable approach, including the combination of hydrothermal and carbonization with chemical activation processes, following by acid impregnation. The targeted catalysts has been applied to facilitate the one-pot conversion of naturally abundant glucose to the high value platform chemical as 5-hydroxymethylfurfural (5-HMF). The essence of employing together of both BrØnsted and Lewis acid catalysts was the key role to exert high production yield of 5-HMF up to $64 \%$ as well as the high glucose conversion of $100 \%$ and 5 -HMF selectivity of $64 \%$ under mild reaction condition.

\section{Introduction}

Biomass has been realized as one of the most abundant source of renewable energy on earth. In recent years, utilization of the biomass as feedstocks for the production of sustainable biofuels and valuable chemicals has been regarded as a promising strategy to deal with limited petroleum reserves and environmental problems [1,2]. Several bio-based carbon, membrane, fiber, and supporting materials have been prepared from biomass to apply in catalysis and variety of applications. Furthermore, high valueadded platform compounds, such as aldehydes and alcohols, can be obtained through pretreatment of biomass materials and subsequently converted into chemicals and liquid fuels for transportation, including gasoline and diesel [3-5]. Among these valuable biomass-derived compounds, 5hydroxymethylfurfural (5-HMF) has been realized as a promising valued-added biomass derived platform 
chemical. As the heterocyclic furanic molecule containing hydroxide and aldehyde functionalities, which is readily transformed into either a dicarboxylic acid or a diol, 5-HMF can be converted to variety of derivatives, serving as the starting material for various valuable intermediate chemicals, including polymers, resins, solvents, building block for the synthesis of biofuels, etc [6] as shown in Fig. 1.

5-HMF can be produced through a sustainably catalytic conversion of the abundant bio-based precursors, as glucose, lignocellulosic compounds, or starch under acidic condition. This process requires a series of reactions, involving firstly the acidic hydrolysis of glucans (i.e. lignocellulosic compounds, or starch) into glucose, following by the isomerization of glucose into fructose over Lewis acid catalysts, and finally the dehydration of fructose to form the targeted 5-HMF product by the assist of Brønsted acid catalysts (the reaction scheme is shown in Fig. 2) [6]. Previously, fructose has been widely researched as the attractive precursor for directly dehydrating into the high 5-HMF yield. However, regarding to its high cost and limited resource, fructose is not applicable for a large scale 5-HMF production. Recently, glucose draws much attention as the promising precursor for the mass production of 5-HMF, due to its abundance with much lower price compared to the fructose and available for attaining quite high yield. In addition, several studies reported a promising 5-HMF yield when the tandem catalytic system where both Lewis and Brønsted acids were simultaneously applied for the conversion of glucose into 5-HMF. For example. Yomaira et al. used the combination of $\mathrm{AlCl}_{3}$ and $\mathrm{HCl}$ catalysts to achieve 5-HMF yield up to $62 \%$ [7]. Rusanen et al. mutually employed the Lewis and BrØnsted solid acid catalysts, prepared from the Zn impregnated and sulfonated birch sawdust derived carbon support, respectively, for producing 5-HMF and attained the highest HMF yield of $51 \%$, with its selectivity of $78 \%$ [8]. Also, solvent systems play an essential role on the 5-HMF production and its selectivity. Especially, biphasic system whereby using the combination of two immiscible reacting phases, e.g. aqueous and organic phases, has been reported for facilitating the high yield and selectivity of 5-HMF, since the produced 5-HMF from aqueous phase readily transfers into organic phase, inhibiting contact between 5-HMF and water, and hence preventing its further conversion to undesired byproducts, such as humins, levulinic acid, or formic acid $[9,10]$. Moreover, it offers a simple 5-HMF separations and a feasibility of system recycling [6]. Thus, to develop an efficient one-pot conversion of glucose to 5-HMF when mutually employing Lewis and BrØnsted acid catalysts, the appropriate solvent system, the ratio of the applied Lewis and BrØnsted acid catalyst, and the related reaction condition (e.g., total catalyst loading, reaction time, etc) are the essential key factors to be optimized with profound understanding.

Nowadays, much of heterogeneous catalytic systems, such as functionalized silica [11-13], zeolites [14], ion-exchange resins [15], and metal oxide [16] have been extensively researched for the 5-HMF production as the results of rendering practical and environmental benign. Nevertheless, these oxide supported catalysts, besides quite expensive, are prone to be unstable in pressurized and hot water, which is a common condition for biomass transformation reactions [17]. This strong condition cause a collapse of structural integrity, leading to decreased catalytic performance, production of contamination when metal leaching to the reacting solution, and difficulty for catalytic recycling. Alternatively, the porous carbon materials generated from the renewable biomass precursors, such as lignocellulosic source, side streams 
and agricultural waste materials [18-20], appear as the potential and sustainable material for preparing the biomass valorization catalysts due to offering low cost, possessing large surface area with highly porous structure, great physical and chemical stability, and capable of surface functionalities by chemical functionalization or impregnation with metals or acidic functional groups to promote catalytic performance [21-24]. This utilization of green approach will also help for carbon neutrality to hold back the climate change crisis. Noteworthy, although so far researches focusing on applying the biomassbased carbon supported solid acid catalysts in various reactions have been broadly investigated, including the esterification of oleic acid with methanol [25], esterification of free fatty acids in waste cooking oil [26], and application for microwave-assisted biodiesel production from waste palm oil [27], only a few works have been dedicated on exploring the utilization of these catalysts for the 5-HMF production.

Thailand is one of the global largest palm oil production countries. After harvesting palm oils for food industries and biofuel production, almost $70 \%$ of the fresh fruit bunches are turned into wastes as the empty fruit bunches, fibers and shells, as well as liquid effluent [28]. It has been estimated that a 100 ton of wastes generated from a typical palm oil mill are composed of about 25 tons of empty fruit bunches, 20 tons of palm kernel shells and 7 tons of fibers $[24,29]$. Since the palm kernel shells have low moisture content and contains residues of palm oil that can provide relatively high heat, they are usually utilized as the biomass solid fuel for steam boiler to run turbines for electricity generation. Meanwhile, the empty palm oil fruit bunch waste typically is not suitable for using as biofuels, due to its high water content up to around $67 \%$, despite containing quite high purity of lingo-cellulosic resource and free from foreign elements, such as gravel, nails, wood residual, waste etc. Thus, most of palm oil empty fruit bunch (POFB) wastes are disposed by landfilling or burnt out, causing current serious air pollution. Hence, the conversion of POFB solid wastes into a value-added product would not only benefit increasing a value of the wastes, but also reducing the air pollution from the burning process. Recently, the POFB solid waste has been mostly exploited as a promising biomass-derived carbon supported acidic catalysts for biodiesel production via esterification process initiating by various feed-stocks, such as waste cooking oils [30], palmitic acid [31], and fatty acid methyl ester [32]. However, only few researches on utilizing the POFB-based carbon supported catalysts for other applications could be found, such as the carbonsupported $\mathrm{CuO}$ catalyst for nitric oxide removal [33], and the Cr-containing activated carbon catalyst for $\mathrm{NH}_{3}$ absorption [34]. Interestingly, it is difficult to search for a work on employing POFB derived carbon supported solid acid catalyst for the catalytic reaction of the value-added 5-HMF production.

Therefore, this work presented the first time mutually utilization of the dual solid acid catalysts (Lewis and Brønsted acid catalysts) prepared from acidic functionalized palm oil empty fruit bunch fiber (POFB) derived porous carbon support for a one-pot conversion of glucose to 5-HMF in a biphasic NMP$\mathrm{H}_{2} \mathrm{O} /$ MIBK system. The porous carbon catalyst support was synthesized by using a combination of hydrothermal treatment and carbonization. Subsequently, to prepare the targeted solid acid catalysts, the obtained porous carbon was acidic impregnated with $\mathrm{AlCl}_{3}$, an aluminium containing precursor, as the Lewis acid catalyst and a $50 \% \mathrm{w} / \mathrm{v} \mathrm{H}_{2} \mathrm{SO}_{4}$ as the Brønsted acid catalyst. The impacts of mass ratio 
between the POFB based biochar to the $\mathrm{KOH}$ activation, combining with the applied carbonization temperature on the morphology of the received porous carbon catalyst support were analyzed. The physical properties of both solid acid catalyst products were thoroughly characterized. Furthermore, the effects of reaction condition, including the aqueous-to-organic phase ratio, the mixing solvent ratio of NMP to water in the aqueous phase, catalyst loading, reaction time, as well as, the impact of simultaneously loading of the Lewis and Brønsted solid acid catalysts on the efficiency of 5-HMF production were investigated. Last but not least, the ability for catalytic reusability by using the proposed solid acid catalytic system under the optimized reaction condition was assessed.

\section{Experimental}

\subsection{Chemicals and materials}

Potassium hydroxide ( $\mathrm{KOH}, \mathrm{AR}$ Grade), sodium hydroxide ( $\mathrm{NaOH}, \mathrm{AR}$ Grade), Aluminium (III) chloride hexahydrate $\left(\mathrm{AlCl}_{3} \cdot 6 \mathrm{H}_{2} \mathrm{O}\right)$ were purchased from Kemaus. Hydrochloric acid ( $\left.\mathrm{HCl} 37 \% \mathrm{wt}, \mathrm{AR} \mathrm{Grade}\right)$, and sulfuric acid $\left(\mathrm{H}_{2} \mathrm{SO}_{4} 98 \%\right.$ wt, AR Grade) were purchased from QRëC. Argon gas (UHP grade) was purchased from SI Technology. 1-methyl-2-pyrrolidinone (NMP), acetonitrile (HPLC grade), and 5hydroxymethylfurfural (AR Grade) for HPLC calibration were purchased from Sigma-Aldrich. Methyl isobutyl ketone (MIBK, AR Grade) was purchased from Merck. D-Glucose (AR Grade) was purchased from Fisher Scientific.

\subsection{Catalyst preparation}

\section{The preparation of palm oil empty fruit bunch derived porous carbon, POFB-PC (catalyst support)}

The palm oil empty fruit bunch fibers (POFB) were separated from palm oil empty fruit bunch by in-house mechanical method. In detail, the shaggy part was collected from the palm oil empty fruit bunch and tore into a bunch of fibers. The collected fruit bunch fibers then was washed with water to remove residual dirt or insects for 3 times and dried at $105^{\circ} \mathrm{C}$ overnight. Subsequently, the dried fibers were ground into smaller pieces before further taken to the pretreatment processes. These POFB were used as the starting material to prepare the porous carbon materials by the combination of hydrothermal process, following by carbonization with $\mathrm{KOH}$ activation. Firstly, $7.5 \mathrm{~g}$ of POFB was immersed in $10 \% \mathrm{w} / \mathrm{v} \mathrm{NaOH}$ for 30 minute to remove lignin and hemi-cellulose. After that, the POFB was washed with DI water until pH 6.57.0, then dried overnight at $105^{\circ} \mathrm{C}$. Subsequently, the dried POFB was soaked in $250 \mathrm{~mL} 0.5 \mathrm{M} \mathrm{H}_{2} \mathrm{SO}_{4}$ and transferred to a $300-\mathrm{mL}$ stainless steel vessel. After heated at $200^{\circ} \mathrm{C}$ for $24 \mathrm{~h}$, the reaction mixture was allowed to slowly cool down to room temperature. The received biochar was washed in DI water until pH about 5.5-6.0 and dried overnight at $105^{\circ} \mathrm{C}$. This biochar was activated by crushing with potassium hydroxide pellet at different mass ratios of biochar to $\mathrm{KOH}$ (e.g. biochar:KOH as 1:2 and 1:3). Furthermore, the mixed sample was carbonized in a tube furnace at a carbonization temperature of 850 ${ }^{\circ} \mathrm{C}$ and $950^{\circ} \mathrm{C}$ for $1 \mathrm{~h}$ under argon atmosphere with a heating rate of $3^{\circ} \mathrm{C} / \mathrm{min}$. After cooled down to room temperature, the obtained porous carbon material was stirred in $0.5 \mathrm{M} \mathrm{HCl}$ overnight, then washed 
in DI water until pH 5.5-6.0. Finally, the porous carbon product was dried overnight in an oven at $105^{\circ} \mathrm{C}$ to achieve the targeted porous carbon product [35]. We assigned the name for the obtained porous carbon samples that were prepared from different mass ratios of $\mathrm{KOH}$ to biochar and the carbonization temperature as $\mathrm{BKxyCz}$. The assigned name was referred to the porous carbon sample that was prepared from the mass ratio of biochar to $\mathrm{KOH}$ as $\mathrm{x}$ to $\mathrm{y}$ and was carbonized at the pyrolysis temperature of $z{ }^{\circ} \mathrm{C}$. For example, $\mathrm{BK} 12 \mathrm{C} 850$ represents for the porous carbon sample prepared by using $\mathrm{KOH}$ activation mass ratio of biochar to $\mathrm{KOH}$ as $1: 2$ and pyrolyzed at $850^{\circ} \mathrm{C}$.

\section{The preparation of Lewis acid and Brønsted acid functionalized-POFB-PC}

Both of the Lewis acid and Brønsted acid functionalized-POFB-PCs were prepared by incipient wetness impregnation. In case of the Lewis acid functionalized-POFB-PC, an $\mathrm{AlCl}_{3} \cdot 6 \mathrm{H}_{2} \mathrm{O}$ salt precursor was used to prepare the $\mathrm{Al}_{2} \mathrm{O}_{3}$ containing Lewis acid catalyst. In detail, 1 to 10 (PC-Im1AILA) and 4 to 10 (PCIm4AILA) mass ratio of the calculated Al metal in the $\mathrm{AlCl}_{3} \cdot 6 \mathrm{H}_{2} \mathrm{O}$ precursor to porous carbon (PC) was dissolved in distilled water. The prepared $\mathrm{AlCl}_{3} \cdot 6 \mathrm{H}_{2} \mathrm{O}$ aqueous solution was dropped onto the POFB-PC and stirred at $60^{\circ} \mathrm{C}$ for about an hour or until the slurry mixture was completely dried. The mixture was then dried overnight at $105^{\circ} \mathrm{C}$. Subsequently, the dried aluminium doped POFB-PC was calcined in a tube furnace at $200^{\circ} \mathrm{C}$ for $3 \mathrm{~h}$ under argon atmosphere with a heating rate of $3^{\circ} \mathrm{C} / \mathrm{min}$ [21]. For the Brønsted acid functionalized-POFB-PC, $50 \mathrm{wt} \% \mathrm{H}_{2} \mathrm{SO}_{4}$ aqueous solution was dispersed in the POFB PC support by mixing the acid solution and the porous carbon support under stirring for about an hour. Likewise, the dried sample was then dried overnight at $105^{\circ} \mathrm{C}$ and further pyrolyzed in a tube furnace at $400{ }^{\circ} \mathrm{C}$ for $3 \mathrm{~h}$ under argon atmosphere with the same heating rate of $3{ }^{\circ} \mathrm{C} / \mathrm{min}$ [21]. This targeted Brønsted acid functionalized-POFB-PC was assigned as PC-Im50BA.

\subsection{Material characterization}

The physical and chemical properties of the acid catalysts were characterized by various characterization methods. The morphology of catalysts were observed by scanning electron microscope (SEM) equipped with energy dispersive spectroscopy (EDS) elemental mapping. $\mathrm{N}_{2}$ adsorption-desorption isotherms were used to characterize the porous structure and the specific surface area based on the adsorption isotherm of the Brunauer-Emmett-Teller (BET) equation. Fourier-transform infrared spectroscopy (FT-IR) was utilized to observe the functional group of the catalysts. X-ray photoelectron spectroscopy (XPS) was performed to identify the binding energies of the loaded metal compounds or the sulfonic functional group to the carbon based material. Ammonia temperature programmed desorption $\left(\mathrm{NH}_{3}\right.$-TPD) was used to determine total acidity of the acidic catalysts. X-Ray Diffractometer (XRD) was employed to determine the crystalline phases of aluminium oxide or sulfonic functionality on the proposed acid catalysts.

\subsection{Conversion of glucose to 5-hydroxy methylfurfural (5-HMF)}

The conversion of glucose to 5-HMF was performed in a batch reactor thereby using temperature controlled shaker. The production of 5-HMF undergone under a bi-phasic reaction, composing of the 
aqueous phase as the combination of N-methyl-2-pyrrolidone (NMP) and water, the organic phase as MIBK solution and the addition of some $\mathrm{NaCl}$. In practical, $0.01 \mathrm{~g}$ of glucose, $0.05 \mathrm{~g}$ of $\mathrm{NaCl}$, acid catalysts responsible by Lewis acid (PC-ImAILA) and Brønsted acid (PC-Im50BA), aqueous phase (NMP and water), and organic phase (MIBK) were loaded in the reactor at ambient temperature, then the reaction temperature was raised and kept steady at $120^{\circ} \mathrm{C}$. After attained a certain period of reaction time, the reaction was quenched in an ice bath at $0{ }^{\circ} \mathrm{C}$ immediately. Subsequently, the loaded catalyst were filtered off and centrifugally washed for 5 times before dried at $60^{\circ} \mathrm{C}$ overnight. The catalyst after washed was meant to be reused with the optimized reaction condition for the catalysis recyclability assessment. Meanwhile, the aqueous and organic layers were separated and taken to analyze their composition by using high performance liquid chromatography (HPLC) [6].

\subsection{Product determination [6]}

The liquid samples collected from batch experiments (section 2.4) were analyzed by high performance liquid chromatography (HPLC). The Sugar HMPcolumn $(3.5 \mu \mathrm{m}, 4.6 \times 100 \mathrm{~mm})$ was used to determine the amount of glucose by using RI detector (model YL9170, YL Instrument). The column oven temperature was maintained by column oven (model TCM-004076, Waters) at $60{ }^{\circ} \mathrm{C}$, and mobile phase was $0.005 \mathrm{M}$ sulfuric acid solution at a flow rate of $0.4 \mathrm{ml} / \mathrm{min}$. The amount of HMF in both layers was determined using UV detector (model 2550, Varian) at the wavelength of $320 \mathrm{~nm}$. The ACE Excel 5 Super C18 reverse phase column $(4.6 \mathrm{~mm} \times 250 \mathrm{~mm}, 5 \mu \mathrm{m}$ particle size, Advanced Chromatography Technologies) was held at $30^{\circ} \mathrm{C}$ and the mobile phase was acetonitrile:water $(10: 90(\mathrm{v} / \mathrm{v}))$ at the flow rate of $0.7 \mathrm{ml} / \mathrm{min}$. The injector (model 7125, Rheodyne) volume of the sample (filtered through $0.45 \mu \mathrm{m}$ Nylon syrings filter membrane) was $20 \mu \mathrm{L}$. The analysis was repeated three times. The conversion of glucose, the yield of 5-HMF, and the selectivity of 5-HMF were calculated as follows:

\section{Conversion of glucose}

Conv. $(\%)=(1-$ (moles of the unreacted glucose/moles of starting glucose units) $) \times 100 \%$ (1)

\section{Yield of 5-HMF}

Y5-HMF $(\%)=($ moles of the produced 5-HMF/moles of starting glucose units) $\times 100 \%$ (2)

\section{Selectivity of 5-HMF}

S5-HMF $(\%)=($ Y5-HMF/Conv. $) \times 100 \%(3)$

\section{Results And Discussion}

\subsection{Material characterization}

The material morphology of the palm oil empty fruit brunch fiber (POFB) starting material and its pretreated sample as well as the obtained activated porous carbon material obtained from different 
activating conditions are illustrated in figure 3 and 4, respectively. By employing the in-house mechanical separation method, the dried POFB had the average fiber diameter of about 200 micron. After pretreated with $\mathrm{NaOH}$, the POFB still showed similar fiber diameter with the pristine one but having rougher surface with grooving structure. The conducted biochar after undergoing the hydrothermal treatment exposed the formation of quite uniform carbon microspheres on the surface of treated POFB. Subsequently, the biochar was further carbonized under different concentrations of $\mathrm{KOH}$ activation and at different carbonization temperatures to investigate their impacts on the morphology of the porous carbon material products.

As seen from fig. 4, the POFB derived porous carbon showed the highly porous with three dimensional interconnecting open channels. At the same carbonization temperature of $850^{\circ} \mathrm{C}$, increasing the concentration of $\mathrm{KOH}$ activation from the mass ratio for the biochar to $\mathrm{KOH}$ as of $1: 2$ (fig. 4a) to 1:3 (fig. $4 b)$ caused the porous carbon wall to collapse or merge with each other, due to the more aggressive oxidation of carbon material into small gas molecule (i.e. $\mathrm{CO}_{2}$, $\mathrm{CO}$, or $\mathrm{H}_{2} \mathrm{O}$ ). This led to larger pore size, and eventually reduced the specific surface area. However, elevating the carbonization temperature from $850^{\circ} \mathrm{C}$ to $950^{\circ} \mathrm{C}$ under using the same amount of $\mathrm{KOH}$ activation as $1: 2$ mass ratio of biochar to $\mathrm{KOH}$ but (shown in fig. 4a and 4c) provided the porous carbon product with an only slightly change of porous structure and their pore sizes. This implied that the applied carbonization temperature seemed to play a less role on the porous structure of the carbon material than the loaded $\mathrm{KOH}$ activating agent. In addition, increasing the carbonization temperature resulted in more sintering of the porous carbon framework, causing some merging of the opened pore edges, illustrated in fig. 4c. Regarding to providing a porous carbon material possessing a uniform 3D interconnected pore with an appropriate pore size, the mass ratio of $1: 2$ biochar to $\mathrm{KOH}$ at the carbonization temperature of $850^{\circ} \mathrm{C}$ was selected as the preparation platform for preparing the porous carbon-based catalyst support to serve for further acid functionalization in the following section.

Furthermore, the porous carbon catalyst support was acidic functionalized via wetness impregnation approach by using $\mathrm{AlCl}_{3}$ and $\mathrm{H}_{2} \mathrm{SO}_{4}$ as the acidic precursor for preparing two Lewis and one $\mathrm{Br} \emptyset$ nsted solid acid catalysts, so called PC-Im1AILA, PC-Im4AILA, and PC-Im50BA, respectively. Fig. 5 shows the SEMs images of material morphology with their active elemental mapping, and their energy dispersive spectroscopic (EDS) spectra for the acid functionalized POFB derived porous carbon material of the representative Lewis and BrØnsted solid acid catalysts (PC-Im4AILA, and PC-Im50BA, respectively). In general, both solid acid catalysts resembled the porous structure of the carbon catalyst support. This may be because only small amount ca. $0.4-9 \mathrm{wt} \%$ of the acidic functional groups could be loaded onto the carbon support surface or some of the impregnated acid went into the inner pores. In addition, the elemental analysis mapping by using energy dispersive spectroscopy (EDS) technique indicated uniform distribution of the functionalized active acidic groups on the porous carbon surface, represented by aluminium and sulfur moieties for the Lewis and BrØnsted acidic functionalities, respectively.

The physisorption isotherms and their pore size distribution of the product samples are illustrated in Fig. 6. Based on the IUPAC classification, the isotherms of the tested samples obviously showed the 
characteristic of type IV physisorption isotherm for multi-scale porous structures that generally facilitate a pore condensation causing the formation of hysteresis in the isotherms. In addition, the shape of hysteresis loops can be assigned for the hysteresis type $\mathrm{H} 4$, showing the pronounce uptake starting at low $\mathrm{p} / \mathrm{p}^{\circ}$ (i.e. $\left.<0.5\right)$. This $\mathrm{H} 4$ hystereis behavior revealed the presence of mesoporous and microporous structure that are often found in the micro-mesoporous carbon material. This exposed multi-scale porous structure agreed well with the previous observed SEM images.

The BET specific surface area $\left(\mathrm{S}_{\mathrm{BET}}\right)$, total pore volume $\left(\mathrm{V}_{\text {total }}\right)$, and average pore size ( $\left.P \mathrm{~S}_{\text {average }}\right)$ of the prepared porous carbon catalyst support and the obtained solid acid catalysts were calculated from $\mathrm{N}_{2}$ adsorption isotherms by Brunauer-Emmett-Teller (BET) method, as reported in Table 1. The porous carbon catalyst support had a high BET surface area of about $1,600 \mathrm{~m}^{2} / \mathrm{g}$. The total pore volume was ca. 1.1 $\mathrm{cm}^{2} . \mathrm{g}^{-1}$ with mesopores having average pore size $\sim 2.7 \mathrm{~nm}$ (mainly ranging around 1.2-4.5 nm). This mesopores would benefit the chemical access during reacting in liquid phase, whereas too small pores can easily be blocked, inhibiting the mass transport. The impregnating solid acid catalysts (PC-Im1 AlLA, PC-Im4AILA, and PC-Im50BA) showed the reduction of the surface area, pore volume, and average pore size compared to their parent porous carbon support. Especially, specific surface area of the corresponding catalyst decreased down to less than $50 \%$ of that of the pristine porous carbon. Moreover, loading more amount of acidic functional group resulted in more reduction of surface area. This might be explained by the pore blocking or more addition of the functional groups into the pore of the carbon support after acidic impregnation

Table 1. Surface morphology of the porous carbon and the solid acid functionalized porous carbon catalyst

\begin{tabular}{|llll|}
\hline Parameters & $\begin{array}{l}\mathrm{S}_{\text {BET }} \\
\left(\mathrm{m} 2 . \mathrm{g}^{-1}\right)\end{array}$ & $\begin{array}{l}\mathrm{V}_{\text {total }} \\
\left(\mathrm{cm}^{3} / \mathrm{g}\right)\end{array}$ & $\begin{array}{l}\text { PS }_{\text {average }} \\
(\AA)\end{array}$ \\
\hline Biochar & 2.9 & 0.02 & 255.8 \\
\hline BK12C850 & $1,599.0$ & 1.1 & 27.2 \\
\hline BK13C850 & $1,417.8$ & 0.8 & 21.4 \\
\hline BK12C950 & $1,108.3$ & 0.6 & 21.6 \\
\hline PC-Im1AILA & 672.9 & 0.4 & 22.4 \\
\hline PC-Im4AILA & 350.3 & 0.3 & 28.7 \\
\hline PC-Im50BA & 292.2 & 0.2 & 22.2 \\
\hline
\end{tabular}


As shown in Fig. 7-8 and Table 2, XPS was performed to further confirm the presence of such active compounds-containing functionality on the catalyst surface, as the aluminium and sulfur -containing functional groups for the proposed Lewis acid catalyst (PC-Im1AILA and PC-Im4AILA) and BrØnsted acid catalyst (PC-Im50BA), respectively. Likewise, the abundance of oxygen and carbon functionalities were also collected. Fig. 7, the rough XPS scan shows main important peaks of binding energy (BE) at about $532,284,170$, and $75 \mathrm{eV}$, corresponding to $01 \mathrm{~s}, \mathrm{C} 1 \mathrm{~s}, \mathrm{~S} 2 \mathrm{p}$ and Al2p, respectively. In Fig. 8, the high resolution deconvoluted spectra of $01 \mathrm{~s}, \mathrm{C} 1 \mathrm{~s}, \mathrm{~S} 2 \mathrm{p}$, and $\mathrm{Al} 2 \mathrm{p}$ were analyzed in order to study the internal chemical bonds combination forms of the acidic group in the catalysts. For all catalysts, the XPS spectrum of $\mathrm{C} 1 \mathrm{~s}$ revealed a relatively high content of carbon functionalities on the surface, as the total C$\%$ was ranging from 69 to 78 atomic conc. \% (see Table 2), relating to $\mathrm{C}-\mathrm{H}, \mathrm{C}-\mathrm{C}, \mathrm{C}=\mathrm{C}, \mathrm{C}=\mathrm{O}, \mathrm{O}-\mathrm{C}=\mathrm{O}$ and $\mathrm{O}=\mathrm{C}-$ $\mathrm{OH}$ at the binding energy of $283.9,284.7,285.8,286.8,288.3$ and $289.3 \mathrm{eV}$, respectively [36-42]. These series of carbon-oxygen binding energies correspond to the emerging of carboxylic functional groups and the natural carbonyl groups of the typical biomass. Though, this observable carbon content seems to be quite lower than that found in typical biomass-based carbon material, which generally contains carbon moiety of 80 to more than $90 \mathrm{wt} . \%$ [43]. A decrease of the normalized carbon content may result from the addition of oxygen functionalities during surface oxidation and some metal impregnation thereby the Lewis acidic functionalization. This was also confirmed by the quite high observable total 0-\% of about 16-26 atomic conc. \% on the catalyst surface (see Table 2). For the deconvoluted XPS spectrum of 01s, the $\mathrm{BE}$ signal at $535.6 \mathrm{eV}$ can correlate to the single-bonded oxygen atoms, e.g. O-H groups of phenol compounds, or even to S-O bonds in such sulfonic acid groups [8]. Moreover, the XPS spectrum peak at about $170 \mathrm{eV}$ for S2p indicated the presence of sulfonic acid groups [44]. It is noteworthy that relatively low concentration of sulfonic group (i.e. based on the $S$ content) could be detected on the surface of the porous carbon support even impregnating with quite high concentration of sulfuric acid $\sim 50 \mathrm{wt}$.\%. This may result from the accelerated elimination of the weak binding sulfonic group on the porous carbon surface under high calcination temperature $>250^{\circ} \mathrm{C}$ [45]. Also, some of the sulfonated compound might impregnate into the inner pores that could not be detected by XPS, causing the substantial reduction of the surface area observed by the BET surface analysis. For the Lewis acid functionalized porous carbon based catalyst, illustrated in Fig 8c, the XPS peaks for Al2p appeared at 76 and $76.9 \mathrm{eV}$, corresponding to the aluminium oxide types as Al-O and $\mathrm{Al}-\mathrm{OH}$, respectively. The addition of Al loading from about 9.1 to $28.6 \mathrm{wt} . \%$ (i.e., $1: 10$ and 4:10 mass ratio of the Al to porous carbon) led to the increment of the impregnated Al within the catalysts from $8.6 \mathrm{wt} . \%$ up to as high as $12.4 \mathrm{wt} . \%$.

Table 2. XPS relative compositions of the BrØnsted and Lewis solid acid catalyst 


\begin{tabular}{|llllllll|}
\hline $\begin{array}{l}\text { Position BE } \\
(\mathrm{eV})\end{array}$ & Peak & PC-Im50BA & & PC-Im1AILA & \multicolumn{3}{c|}{ PC-Im4AILA } \\
\cline { 3 - 8 } & & $\begin{array}{l}\text { Atomic conc. } \\
(\%)\end{array}$ & Mass & $\begin{array}{l}\text { Atomic conc. } \\
(\%)\end{array}$ & $\begin{array}{l}\text { Mass } \\
(\%)\end{array}$ & $\begin{array}{l}\text { Atomic conc. } \\
(\%)\end{array}$ & $\begin{array}{l}\text { Mass } \\
\text { conc. } \\
(\%)\end{array}$ \\
\hline 532.3 & O1s & 26.4 & 32.0 & 15.8 & 18.6 & 22.6 & 25.2 \\
\hline 284.3 & C1s & 72.9 & 66.3 & 78.0 & 68.6 & 68.9 & 57.7 \\
\hline 199.3 & Cl2p & - & - & 1.0 & 2.7 & 1.9 & 4.7 \\
\hline 170.0 & S2p & 0.7 & 1.7 & - & - & - & - \\
\hline 75.3 & Al2p & - & - & 4.4 & 8.6 & 6.6 & 12.4 \\
\hline
\end{tabular}

In Fig. 9, the metal oxide and sulfonate phases of the impregnated Lewis and BrØnsted solid acid catalysts were further observed by XRD technique. In all catalysts, the broad XRD peaks at around $2 q=$ $25^{\circ}$ and $44^{\circ}$ are referred to the amorphous carbon phase (JCPDS file no. 01-082-9929) [8]. For the BrØnsted acid (Fig 9a), crystalline phases of the sulfonic acid group were observed at $2 \mathrm{q}$ of $15.1^{\circ}, 20.9^{\circ}$, $25.9^{\circ}, 30.6^{\circ}, 32^{\circ}, 33.6^{\circ}, 34.3^{\circ}, 40.9^{\circ}, 42.6^{\circ}, 44.2^{\circ}, 52.7^{\circ}, 55.3^{\circ}, 56.3^{\circ}, 57.1^{\circ}, 60.5^{\circ}, 65^{\circ}$, and $68.5^{\circ}$, which were attributed to the crystalline ordered planes at (012), (104), (021), (024), (107), (116), (211), (303), (208), (119), (401), (1210), (317), (045), (234), (3110), and (1311), respectively. In case of the Lewis acid catalysts (Fig 9b (PC-Im4AILA) and 9c (PC-Im1AILA)), the peaks at 2q of 25.5, 35. ${ }^{\circ}, 37.7^{\circ}, 41.6^{\circ}$, $52.5^{\circ}, 57.4^{\circ}, 66.5^{\circ}$, and $68.1^{\circ}$ revealed the presence of aluminium oxide phase, respecting to the $\mathrm{Al}_{2} \mathrm{O}_{3}$ ordered planes at (012), (104), (110), (006), (024), (116), (214), and (300), respectively. $\mathrm{No} \mathrm{AlCl}_{3}$ or $\mathrm{Al}$ metal were detected, indicating that the $\mathrm{AlCl}_{3}$ was completely removed or bonded to the oxygen functional groups on the carbon support under the applied calcination temperature. Adding more $\mathrm{AlCl}_{3}$ precursor for the PC-Im4AILA sample clearly resulted in greater amount of forming crystalline $\mathrm{Al}_{2} \mathrm{O}_{3}$ phase within the Lewis acid catalyst product. This could be observed by its higher XRD intensity comparing to that of lower $\mathrm{Al}_{2} \mathrm{O}_{3}$ loaded sample, as the PC-Im1 AILA.

The FTIR technique was mainly employed to analyze the functional groups relating to the Brønsted acid. In Fig. 10, compared to that of the Lewis acid catalyst (PC-Im4AILA) and the porous carbon support (BK12C850), the conducted FTIR spectra of the proposed sulfonic acid functionalized catalyst (PCIm50BA) exposed a clearly new emerging peak at $625 \mathrm{~cm}^{-1}, 1114 \mathrm{~cm}^{-1}$, and $1632 \mathrm{~cm}^{-1}$, which were associated with the $\mathrm{O}-\mathrm{H}, \mathrm{S}=\mathrm{O}$ and $\mathrm{C}=\mathrm{C}$ stretching vibrations of the sulfonic acid group, respectively [3637,46-48]. This appearance of sulfur, oxygen, and carbon bonding groups verified the success of the $\mathrm{SO}_{3} \mathrm{H}$ functionalization in the porous carbon support that was also consistent with the previous XPS and the XRD results. In addition, the strong FTIR peaks located at $3465 \mathrm{~cm}^{-1}$ and $1720 \mathrm{~cm}^{-1}$ were observed in all tested samples, indicating the presence of the $\mathrm{O}-\mathrm{H}$ stretching and the $-\mathrm{COOH}$ groups, respectively 
[49]. The formation of these oxygenated functional groups may result from the surface oxidation during the sulfuric acid treatment in the hydrothermal step, when preparing the biochar from the palm oil fruit bunch fibers raw material. This presence of oxygen functionalities was also detected by XPS. It is worth mentioning that these conducted FTIR signals of the hydroxyl and the carbonyl vibrations may also overlap with the natural oxy and carbonyl moieties that were generally found in the biomass material.

The type and total amount of acid sites on the surface of the POFB derived porous carbon support, the prepared Brønsted acid (PC-Im50BA) and Lewis acid (PC-Im1AILA and PC-Im4AILA) catalysts were determined by temperature-programmed desorption of ammonia $\left(\mathrm{NH}_{3}-\mathrm{TPD}\right)$. The position of desorption peaks is responsible for the acid strength, while its area correlates to the acid amount. The ammonia desorption process was monitored up to $710^{\circ} \mathrm{C}$. As seen from the TPD profile in Fig. 11, roughly there are distinct $\mathrm{NH}_{3}$ desorption peaks around $100-125^{\circ} \mathrm{C}$ and $450-600{ }^{\circ} \mathrm{C}$ for all samples, and additionally the very strong sharp peak at more than $600^{\circ} \mathrm{C}$ for only the BrØnsted acid (PC-Im50BA) sample. The required relatively low desorption temperatures of around $100-125^{\circ} \mathrm{C}$ correlated to the $\mathrm{NH}_{3}$ desorption process from weak acids, as carboxylic acids, lactone, lactols or phenols, and anhydrides. These weak acidic groups are typically seen in activated carbon or somehow generated via surface oxidation [43], as previously mentioned. Comparing to the other samples, the PC-Im50BA obviously showed strong sharp desorption peaks mostly at high temperature of 614 and $705^{\circ} \mathrm{C}$, which can be attributed to the $\mathrm{NH}_{3}$ desorption from strong BrØnsted acid sites [50]. Additionally, it also expressed the trace amount of weaker desorption signal at the weak acid region, shown as desorption peak at $107^{\circ} \mathrm{C}$. This confirms the success and effective strong sulfonic acid functionalization on the porous carbon support through the concentrated sulfuric acid (50 wt\%) impregnation process. This accumulation of the large amount of strong Brønsted acid content in conjunction with some weak acidic functionalities led to the high total acidic content up to $13 \mathrm{mmol} . \mathrm{g}^{-1}$. For both Lewis acid samples (PC-Im1AILA and PC-Im4AILA), two $\mathrm{NH}_{3}$ desorption processes could be detected at temperature around $123-125^{\circ} \mathrm{C}$ and $450-600^{\circ} \mathrm{C}$, corresponding to the weak acidic groups and thermally stable Lewis acid sites, respectively. Interestingly, the PCIm4AILA sample with slightly more Lewis acidic loading content-6.6 atomic loading\% for PC-Im4AILA comparing to 4.4 atomic loading\% for PC-Im1AILA, showed extensively more thermally stable functional groups, as shifting the desorption energy at $\sim 460^{\circ} \mathrm{C}$ for PC-Im1AlLA to much higher desorption energy at $\sim 588^{\circ} \mathrm{C}$ for PC-Im4AILA. In addition, more content of Lewis acid groups may facilitate more formation of oxygen-bearing functionalities, appearing as more amount of the weak acid in the $\mathrm{NH}_{3}$ desorption at 123$125^{\circ} \mathrm{C}$. This exerted greater amount of acid sites as $2.4 \mathrm{mmol} . \mathrm{g}^{-1}$ for PC-Im4AILA, comparing to 2.0 for PC-Im1AILA. In the case of porous carbon support, there were combination of acid sites shown in the weak acidic region (i.e. desorption peak at $122^{\circ} \mathrm{C}$ ), attributed to natural oxygen-bearing functional groups in typical biomass, and probably some introduced by dilute sulfuric acid treatment during hydrothermal process, and also the relatively high thermally stable acidic functional groups shown as desorption at $594^{\circ} \mathrm{C}$. The total amount of acidic sites for the porous carbon support were $1.78 \mathrm{mmol}^{-1} \mathrm{~g}^{-1}$, suggesting high amount of acid sites generated during the proposed porous carbon preparation procedure. Regarding to morphology and the amount of functionalized acid sites, PC-Im4AILA and PC-Im50BA were 
selected as the Lewis and BrØnsted solid acid catalysts for further investigating catalytic performance of glucose conversion to $5-\mathrm{HMF}$ in the next section.

Table 3. The acidity of fresh porous carbon support (BK12C850), and the solid acid catalysts PC-Im1 AlLA, PC-Im4AILA, and PC-Im50BA.

\begin{tabular}{|c|c|c|c|c|}
\hline $\begin{array}{l}\text { Temp. } \\
\text { Samples }\end{array}$ & $\begin{array}{l}100-300^{\circ} \mathrm{C} \\
\left(\mathrm{mmol} . \mathrm{g}^{-1}\right)\end{array}$ & $\begin{array}{l}301-500^{\circ} \mathrm{C} \\
\left(\mathrm{mmol} . \mathrm{g}^{-1}\right)\end{array}$ & $\begin{array}{l}501-700^{\circ} \mathrm{C} \\
\left(\mathrm{mmol} . \mathrm{g}^{-1}\right)\end{array}$ & $\begin{array}{l}\text { Total acidity (mmol.g } \\
\text { 1) }\end{array}$ \\
\hline BK12C850 & $\begin{array}{l}0.7(121.9 \\
\left.{ }^{\circ} \mathrm{C}\right)\end{array}$ & - & $1.1\left(593.8^{\circ} \mathrm{C}\right)$ & 1.8 \\
\hline $\begin{array}{l}\text { PC- } \\
\text { Im1AILA }\end{array}$ & $\begin{array}{l}0.5(123.4 \\
\left.{ }^{\circ} \mathrm{C}\right)\end{array}$ & $\begin{array}{l}1.5(459.7 \\
\left.{ }^{\circ} \mathrm{C}\right)\end{array}$ & - & 2.0 \\
\hline $\begin{array}{l}\text { PC- } \\
\text { Im4AILA }\end{array}$ & $\begin{array}{l}0.9(125.1 \\
\left.{ }^{\circ} \mathrm{C}\right)\end{array}$ & - & $1.5\left(588.2^{\circ} \mathrm{C}\right)$ & 2.4 \\
\hline $\begin{array}{l}\text { PC- } \\
\text { Im50BA }\end{array}$ & $\begin{array}{l}0.3(107.4 \\
\left.{ }^{\circ} \mathrm{C}\right)\end{array}$ & - & $\begin{array}{l}2.4\left(613.6^{\circ} \mathrm{C}\right), 10.3(704.7 \\
\left.{ }^{\circ} \mathrm{C}\right)\end{array}$ & 13.0 \\
\hline
\end{tabular}

Note: The number in parentheses are the peak positions of the $\mathrm{NH}_{3}$ desorption temperatures

\subsection{Catalytic determination}

\section{Effect of aqueous and organic phase ratio}

Fig. 12 shows the effect of aqueous to organic phase ratio on the production yield of 5-HMF, conversion of glucose, and selectivity toward 5-HMF. In the biphasic system, methyl isobutyl ketone (MIBK) has been used as the organic solvent to readily collect the generated 5-HMF product before further undergoing undesired side reactions in the aqueous phase. Therefore, for this study we employed the biphasic system of $\mathrm{NMP} / \mathrm{H}_{2} \mathrm{O}$ (mixed solvent in aqueous phase) and MIBK (organic phase) for investigating the conversion of glucose to $5-\mathrm{HMF}$ in a batch reaction. The volume ratio of $\mathrm{NMP} / \mathrm{H}_{2} \mathrm{O}$ aqueous phase to the MIBK organic phase was varied from 1:1 to 1:4, while the total volume of the bi-phasic solvent mixture was constant at $1 \mathrm{~mL}$. The amount of Lewis acid (PC-Im4AILA), Bronsted acid (PC-Im50BA), glucose, and $\mathrm{NaCl}$ were constant at $0.005 \mathrm{~g}, 0.04 \mathrm{~g}, 0.01 \mathrm{~g}$, and $0.05 \mathrm{~g}$, respectively. The reaction time, temperature and $\mathrm{NMP} / \mathrm{H}_{2} \mathrm{O}$ ratio were held constant at $60 \mathrm{~min}, 120^{\circ} \mathrm{C}$ and $1: 1$, respectively. It was found that increasing the volume ratio of organic phase to aqueous phase resulted in the increase of glucose conversion, 5HMF production yield as well as the selectivity through $5-\mathrm{HMF}$, according to the readily transfer of 5-HMF from aqueous to organic phase that prevents the favorable side reactions of 5-HMF within the aqueous phase $[51,52]$. The 5 -HMF produced in the aqueous phase is favorable to be extracted by the organic 
solvent, leading to the loss of 5-HMF in the aqueous reacting phase. The reduction of the 5-HMF in aqueous phase will drive the equilibrium to promote more production of the 5-HMF product. In addition, surrounding by the organic solvent can inhibit the contact of 5-HMF with water molecules, resulting in a less possible rehydration to form undesired byproducts. The excess water in the system can promote the formation of levulinic and formic acids due to the rehydration of 5-HMF with the vast amount of surrounding water molecules [1]. However, lowering aqueous-to-organic phase ratio from 1:3 to 1:4 would reduce the 5 -HMF yield from $20.19 \%$ to $18.50 \%$ and selectivity from $50.68 \%$, to $34.13 \%$ because, more or less, glucose still needed an appropriate water amount to transform into fructose via isomerization. Insufficient water content caused the increase of glucose concentration in the aqueous system that would accelerate the cross-polymerization of glucose into humins. Alternatively, high concentration of the glucose starting material will probably drive reaction to produce more fructose and continuing support the formation of 5-HMF under the appropriate amount of the related catalysts. However, the appearance of too concentrated fructose or 5-HMF in the system could eventually also promote their own crosspolymerization into humins (see Fig.2) [1]. Based on the received highest 5-HMF product yield, the 1:3 aqueous to organic phase volume ratio was used as the base amount of the applied biphasic system for following optimization of other related parameters.

\section{Effect of NMP to $\mathrm{H}_{2} \mathrm{O}$ ratio}

The effect of $\mathrm{NMP} / \mathrm{H}_{2} \mathrm{O}$ volume ratio was subsequently investigated to improve the reaction performance for the synthesis of 5-HMF as illustrated in Fig. 13. The $\mathrm{NMP} / \mathrm{H}_{2} \mathrm{O}$ volume ratio was varied from 1:1 to 4:1, while the $1: 3$ aqueous to organic phase volume ratio, $0.005 \mathrm{~g}$ of PC-Im4AILA, $0.04 \mathrm{~g}$ of PC-Im50BA, the reaction temperature of $120^{\circ} \mathrm{C}$, and the reaction time of $60 \mathrm{~min}$ were held constant. The result indicated that increasing the NMP to $\mathrm{H}_{2} \mathrm{O}$ volume ratio from 1:1 to 4:1 provided more glucose conversion, as well as the yield of 5-HMF production, and mostly selectivity of 5-HMF. This may be explained that NMP can facilitate the favorable formation of the more stable form of fructose into fructofuranose via tautomerization. The forming fructofuranose form is readily to be converted to 5-HMF, hence eventually enhancing the production of the 5-HMF product. However, at the same time, under the presence of a BrØnsted acidic catalyst, the generated 5-HMF could possibly be protonated, and further dehydrated to form a reactive carbonium ion intermediate. This HMF intermediate form could also react with several other intermediates, such as fructose or 5-HMF itself, to form humins or other oligomeric by-products [53], hence leading to a great reduction of the HMF selectivity when increasing the amount of NMP addition, as indicated by the substantial decrease of the selectivity when increasing the NMP portion from 1:1 to 2:1 NMP to $\mathrm{H}_{2} \mathrm{O}$ volume ratio. As the results, continuingly increasing the $\mathrm{NMP} / \mathrm{H}_{2} \mathrm{O}$ volume ratio to $4: 1$ could only slightly increase both 5-HMF yield and selectivity, while boosting up the glucose conversion up to $92.46 \%$. This was because basically NMP acted as an aqueous phase modifier, preventing the generation of humins or other by-products, such as levulinic acid, and formic acid, via rehydration of the 5-HMF in water. As an aprotic organic solvent, NMP also simultaneously enlarges the partitioning of 5HMF into the organic phase [10]. Considering from all comparable production indicators, including 5-HMF production yield, glucose conversion, and 5-HMF selectivity, consuming saver amount of NMP as the 
case of using 3:1 NMP/ $\mathrm{H}_{2} \mathrm{O}$ volume ratio has been chosen, though the 4:1 NMP/ $\mathrm{H}_{2} \mathrm{O}$ volume ratio could provide a little higher yield for all production parameters.

\section{Effect of catalyst loading}

The amount of catalyst loading is another important factor that determines the production efficiency. Especially in our specific case, since the conversion of glucose to 5-HMF occurs through two consecutive acid catalytic reactions (i.e. isomerization and dehydration) that require both Lewis acid and Bronsted acid catalysts, hence it also necessitates to optimize a suitable ratio of the applied dual acidic catalysts. As shown in Fig. 14, the effect of catalyst loading and the ratio of simultaneously applied Lewis acid and BrØnsted acid catalysts on the 5-HMF production efficiency has been investigated. In this study, the total amount of both catalysts was varied from 35 to $60 \mathrm{mg}$ to explore the appropriate amount and ratio of the dual solid acid catalysts. Roughly, increasing amount of total catalysts resulted in more production yield. Considering in detail, increasing the amount of BrØnsted acid catalyst (PC-Im50BA), while keeping amount of Lewis acid catalyst (PC-Im4AILA) constant, enhanced the 5-HMF production yield, its selectivity as well as the total glucose conversion. This indicated that the fructose generated from the isomerization of glucose in the initial step was readily transformed into 5-HMF under the presence of more BrØnsted acid catalyst in the following dehydration step. Noteworthy, under a strong acidic condition, BrØnsted acid catalyst can also directly assist the dehydration of glucose into the 5-HMF, bypassing the Lewis acid catalyzed glucose-fructose isomerization [54]. The synergistic effects of mutually using Lewis and BrØnsted acid catalysts may lead to the high obtained glucose conversion in the order of $90-93 \%$. In contrary, while using same amount of BrØnsted acid catalysts, increasing the Lewis acid catalyst resulted in slightly decrease of the 5-HMF yield and its selectivity, but rather increase the glucose conversion. This may be explained by that the activated isomerization reaction, from adding more amount of Lewis acid catalyst, would promote more conversion of glucose into fructose. However, more concentration of forming fructose may probably support more cross-polymerization of fructose into humins, causing lower fructose for further dehydration into 5-HMF product. As the catalyst loading aspect, we chose the total catalyst loading of $45 \mathrm{mg}$ with the mass ratio of Lewis and BrØnsted acid catalysts as 0.005 to $0.04 \mathrm{~g}$ for further optimizing of reaction time based on the quite high 5-HMF yield and its selectivity (i.e. $27.0 \%$ and $29.9 \%$, respectively) at a saver amount of employed catalysts.

\section{Effect of reaction time}

Finally, the effect of reaction time for the reaction performing under the previous optimized reaction condition was explored to maximize the targeted 5-HMF production performance. In Fig. 15, a set of reacting time varied from $1 \mathrm{~h}$ to $8 \mathrm{~h}$ under reaction temperature of $120^{\circ} \mathrm{C}$ with the aqueous to organic phase volume ratio of 1:3, NMP to $\mathrm{H}_{2} \mathrm{O}$ volume ratio of $3: 1,0.05 \mathrm{~g}$ of $\mathrm{NaCl}, 0.005 \mathrm{~g}$ of PC-Im4AILA, and $0.04 \mathrm{~g}$ of PC-Im50BA was performed. The conversion of glucose, 5-HMF yield, and 5-HMF selectivity increased with reaction time from $1 \mathrm{~h}$ to $6 \mathrm{~h}$. However, with a longer reaction time up to $8 \mathrm{~h}$, the yield and 
selectivity of 5-HMF dropped to $57.66 \%$ while the conversion of glucose was nearly constant. This can be explained that a great extent of 5-HMF was further converted to byproducts, such as polymers, livulinic acid, formic acid, and humins due to the prolonged reaction time [7]. For instance, the produced 5-HMF can undergo a further rehydration to form byproducts, such as a levulinic acid or formic acid [55]. In addition, under the strong BrØnsted acidic condition, the 5-HMF can also be deprotonated and dehydrated into the intermediate form that is readily to react with other existing sugars, such as glucose and fructose. The condensation polymerization of 5-HMF with these sugars results in the formation of oligomers, as soluble polymers and insoluble humins [56]. Therefore, The optimized condition that provided the highest glucose conversion (100\%), 5-HMF yield (63.88\%), 5-HMF selectivity (63.88\%) were obtained by $0.01 \mathrm{~g}$ of glucose, $0.05 \mathrm{~g}$ of NaCl, catalyst ratio of 0.005 to 0.04 (PC-Im4AILA to PC-Im50BA), aqueous to organic phase volume ratio of $1: 3$, and $\mathrm{NMP}$ to $\mathrm{H}_{2} \mathrm{O}$ volume ratio of $3: 1$, under $120^{\circ} \mathrm{C}$, and reacting time for $6 \mathrm{~h}$.

\section{Effect of dual applied Lewis and Brønsted solid acid catalysts}

In this section, the impact of simultaneously using dual acidic catalysts on the catalytic performance for 5 -HMF production was investigated. The obtained 5-HMF production performance from reactions run by various sets of solid acid catalysts under the optimized reaction condition from the previous study in prior section are illustrated in Fig. 16. The catalytic reaction that was run by the bare POFB based activated porous carbon was utilized as the reference reaction and only $0.39 \% 5$-HMF yield was received. The small production of 5-HMF may result from the help of some oxygen-bearing groups working as weak acids and the added $\mathrm{NaCl}$ that has been reported for its participation in catalyzing 5-HMF production, where the chloride ions could enhance the isomerization of glucose to fructose and also dehydration of fructose to 5-HMF [57]. Solely using Lewis acid catalyst, as only either PC-Im1 AlLA or PCIm4AILA, seemed to just a little improve the 5-HMF production performance by increasing the yield to about $3.66 \%$ and $13.21 \%$, respectively. More production of 5-HMF when carried out by using PC-Im4AILA catalyst compared to that of received by PC-Im1AILA can reasonably be explained by its more functionalized Lewis acid sites on the porous surface, confirmed by the XPS results. It is worth noting that the PC-Im4AILA could significantly deliver higher 5-HMF yield than PC-Im1AILA even possessing considerably less surface area. This may imply the more essential role of the active acid sites than the surface area for the case of acidic catalyst. The better production performance of 5-HMF may be according to the presence of Lewis acid catalyst that facilitate the conversion of glucose into fructose and then the generated fructose might be able to transform to 5-HMF by the containing weak acid functionality on the porous carbon support. In addition, without the BrØnsted acid catalyst, further transformation of fructose into 5-HMF was limited due to a less reactivity, hence delivering quite high glucose conversion (50.6\%) but relatively low 5-HMF yield (13.2\%). On the other hand, applying only BrØnsted acid catalyst could substantially enhance the 5-HMF yield up to about $51.10 \%$, which increased more than 30 percentage unit comparing to the case of solely using Lewis acid catalyst even with high acidic site (PC-Im4AILA). This may be explained by that the BrØnsted acid catalyst itself can also facilitate the direct dehydration of glucose into a reactive 5-membered ring intermediate that is readily to be further dehydrated into the 5-HMF product as mentioned in the previous section. In addition, with the 
assisting of $\mathrm{NaCl}$, the loading $\mathrm{NaCl}$ may function as substituted Lewis acid to support the conversion of glucose to fructose and it was readily transform to 5-HMF under the presence of the applied BrØnsted acid catalyst (PC-Im50BA). Utilizing dual Lewis and BrØnsted acid catalysts clearly enhanced the performance of 5-HMF production to more than $60 \mathrm{yield} \%$, as well as boosted up the glucose conversion and the HMF selectivity, regarding to the effective conversion of both glucose isomerization into fructose by Lewis acid catalysts and then dehydration of fructose to 5-HMF by Brønsted acid catalysts. As expected, employing combination of the BrØnsted acid catalysts and the Lewis acid catalyst with more acid sites as PC-Im4AILA would exert more 5-HMF yield (up to 63.88\%) due to its higher active acidic groups that was consistent with the results derived from using solely Lewis acid catalyst. In conclusive, using the bi-acidic solid acid catalysts was the effective approach to promote the production of 5-HMF from glucose via a practical batch one-pot conversion of glucose to 5-HMF reaction.

\section{Spent catalyst characterization}

The spent dual solid acid catalyst system (PC-Im4AILA + PC-Im50BA) after first and third reused for the acidic catalytic glucose to 5 -HMF conversion under the optimized reaction condition were retrieved to elucidate their physicochemical changes via SEM equipped with the EDS elemental mapping, XPS, and the acidity analysis using $\mathrm{NH}_{3}$-TPD. Fig. 17 demonstrates SEM images with their composing elemental mapping of the used catalysts to observe any morphology changes and the residual acidic functionalities represented as $\mathrm{Al}, \mathrm{S}, \mathrm{O}$, and $\mathrm{C}$ moieties. The spent catalysts even after reused for 3 times still retained the morphology of their respective fresh catalysts (referring to Fig. 5.), judging from the observed similar mesoporous structure. Obviously, the presence of residual active acidic functional groups, such as $\mathrm{Al}_{2} \mathrm{O}_{3}$ and sulfonic acid, representing by $\mathrm{Al}, \mathrm{S}$, and $\mathrm{O}$ elements could also be detected on surface of the used catalysts. However, it could not exactly determine the quantity of the acidic group by only relying on the rough EDS mapping display.

Furthermore, XPS was employed to investigate the presence of the residual active acidic functional groups and the change of their binding interaction of the recycled acid catalysts. The comparison of the residual acidic functionalities and their corresponding binding interaction for the spent catalysts and their parent fresh catalysts was summarized in Table 4. Clearly, the Lewis and Brønsted acidic groups were consumed during several uses, observed by the loss of $\mathrm{Al}$ and $\mathrm{S}$ as well as the related $\mathrm{O}$ functionalities. Though, after the $3^{\text {rd }}$ recycled the Al content within the spent catalysts could be observed in the EDS mapping, with a much lower detection depth for the XPS surface analysis technique, the very little amount of the surface Al functional groups led to its normalized content closing to zero, as summarized in the Table 4. This reduction of the active acid group caused the increase of the normalized $C$ content. The greater decrease of the surface residual Al functional groups implied that the surface Lewis acid might have been consumed faster than the Brønsted acids, or readily detached from the porous carbon support surface, regarding to its weaker binding energies. Interestingly, all acidic functional groups within the spent catalyst exhibited lower binding energies compared to its comprising fresh catalyst. This might suggest that the binding interaction between the functionalized acidic groups were weaken after each consecutively used.

Page $17 / 43$ 
Table 4. XPS relative compositions of the spent catalyst system by using X-ray photoelectron spectroscopy (XPS)

\begin{tabular}{|c|c|c|c|c|c|c|}
\hline \multirow[t]{4}{*}{ Peak } & \multicolumn{3}{|c|}{ Fresh acid catalysts } & \multicolumn{3}{|c|}{$\begin{array}{l}\text { Spent catalyst system (PC-Im4AILA+ PC- } \\
\text { Im50BA) }\end{array}$} \\
\hline & \multirow[t]{3}{*}{$\begin{array}{l}\text { Position BE } \\
(\mathrm{eV})\end{array}$} & PC-Im50BA & PC-Im4AILA & \multirow[t]{3}{*}{$\begin{array}{l}\text { Position BE } \\
(\mathrm{eV})\end{array}$} & $\begin{array}{l}1^{\text {st }} \\
\text { recycled }\end{array}$ & $\begin{array}{l}3^{\text {rd }} \\
\text { recycled }\end{array}$ \\
\hline & & $\begin{array}{l}\text { Atomic conc. } \\
(\%)\end{array}$ & $\begin{array}{l}\text { Atomic conc. } \\
(\%)\end{array}$ & & $\begin{array}{l}\text { Atomic } \\
\text { conc. }\end{array}$ & $\begin{array}{l}\text { Atomic } \\
\text { conc. }\end{array}$ \\
\hline & & & & & (\%) & (\%) \\
\hline 01s & 532.3 & 26.4 & 22.6 & 530 & 38.3 & 31.3 \\
\hline $\mathrm{C} 1 \mathrm{~s}$ & 284.3 & 72.9 & 68.9 & 282 & 55.0 & 67.7 \\
\hline $\mathrm{Cl} 2 \mathrm{p}$ & 199.3 & - & 1.9 & NA & - & - \\
\hline S2p & 170 & 0.7 & - & 167 & 3.1 & 1.0 \\
\hline Al2p & 76 & - & 6.6 & 72 & 3.6 & 0.0 \\
\hline
\end{tabular}

The change of acidities for the spent catalyst was analyzed by using $\mathrm{NH}_{3}$-TPD. The comparison of the $\mathrm{NH}_{3}$ desorption isotherms and their acidity detail between the $1^{\text {st }}$ and $3^{\text {rd }}$ recycled catalysts, and their starting fresh acid catalysts is illustrated in Fig. 18 and summarized in Table 6, respectively. Roughly, both Lewis and BrØnsted acidic functional groups have been substantially used during the glucose conversion, observed by the great reduction of the total acidity from $\sim 13 \mathrm{mmol} . \mathrm{g}^{-1}$ to $3.7 \mathrm{mmol} . \mathrm{g}^{-1}$ since the first reuse (see Table 6). Comparing to the fresh BrØnsted acid catalyst (PC-Im50BA) sample, the strongest $\mathrm{Br} \varnothing \mathrm{nsted}$ acid site, initially found at the $\mathrm{NH}_{3}$ desorption temperature $\sim 705^{\circ} \mathrm{C}$, was gone since even after first recycling. Likewise, another desorption signal of a strong acidic BrØnsted functionality at $\sim 614{ }^{\circ} \mathrm{C}$ also significantly decreased since the first use. A plausible explanation was these strong BrØnsted acidic functional groups, referring to the sulfonic acid functionality, might readily involve in the reaction from the early cycles. The reduction of the desorption peak shoulder starting from $\sim 400{ }^{\circ} \mathrm{C}$ to $\sim 500^{\circ} \mathrm{C}$ for the spent catalyst, respect to its composing fresh Lewis acid catalyst (PC-Im4AILA), indicated a consumption of the strong Lewis acid site (shown at $\mathrm{NH}_{3}$ desorption temperature $\sim 600^{\circ} \mathrm{C}$ ) during the reaction. Interestingly, the peak of weak acidic groups, showing at the desorption peak around $125^{\circ} \mathrm{C}$, for the Lewis acid catalyst in the used catalyst system considerably reduced compared the corresponding fresh catalyst one, implying a great consuming of this Lewis acidic functionality for catalyzing the reaction. In contrary, the weak BrØnsted acidic signal of the recycled catalyst system that appeared in the same region showed only slightly decrease compared to the starting fresh BrØnsted acid. This suggested 
that the main BrØnsted acidic groups that play a role in the reaction may mostly be the strong sulfonic acidic functionality.

Table 6. The comparison of acidity between the spent catalyst systems (PC-Im4AILA + PC-Im50BA) and its composing fresh solid acid catalysts (PC-Im4AILA, and PC-Im50BA) analyzed by $\mathrm{NH}_{3}$-TPD

\begin{tabular}{|c|c|c|c|c|}
\hline $\begin{array}{ll} & \text { Temp. } \\
\text { Samples } & \end{array}$ & $\begin{array}{l}100-300^{\circ} \mathrm{C} \\
(\mathrm{mmol} / \mathrm{g})\end{array}$ & $\begin{array}{l}301-500 \\
{ }^{\circ} \mathrm{C} \\
(\mathrm{mmol} / \mathrm{g})\end{array}$ & $\begin{array}{l}501-700^{\circ} \mathrm{C} \\
(\mathrm{mmol} / \mathrm{g})\end{array}$ & $\begin{array}{l}\text { Total acidity } \\
(\mathrm{mmol} / \mathrm{g})\end{array}$ \\
\hline \multicolumn{5}{|l|}{ Fresh sample } \\
\hline PC-Im4AILA & $\begin{array}{l}0.9(125.1 \\
\left.{ }^{\circ} \mathrm{C}\right)\end{array}$ & - & $1.5\left(588.2^{\circ} \mathrm{C}\right)$ & 2.4 \\
\hline PC-Im50BA & $\begin{array}{l}0.3(107.4 \\
\left.{ }^{\circ} \mathrm{C}\right)\end{array}$ & - & $\begin{array}{l}2.4\left(613.6^{\circ} \mathrm{C}\right), 10.3 \\
\left(704.7^{\circ} \mathrm{C}\right)\end{array}$ & 13.0 \\
\hline \multicolumn{5}{|c|}{ Spent catalyst system } \\
\hline $\begin{array}{l}1^{\text {st }} \text { recycled } \\
\text { (PC-Im4AILA+PC- } \\
\text { Im50BA) }\end{array}$ & $\begin{array}{l}0.3(131.5 \\
\left.{ }^{\circ} \mathrm{C}\right)\end{array}$ & - & $3.4\left(615^{\circ} \mathrm{C}\right)$ & 3.7 \\
\hline $\begin{array}{l}3^{\text {rd }} \text { recycled } \\
\text { (PC-Im4AILA+PC- } \\
\text { Im50BA) }\end{array}$ & $\begin{array}{l}0.2(119.9 \\
\left.{ }^{\circ} \mathrm{C}\right)\end{array}$ & - & $2.9\left(614.3^{\circ} \mathrm{C}\right)$ & 3.1 \\
\hline
\end{tabular}

Note: The numbers in parentheses are the peak positions of the $\mathrm{NH}_{3}$ desorption temperatures

\section{Preliminary catalyst recyclability assessment}

The catalyst recyclability is essentially important for the practical 5-HMF production. The results of our solid acid catalysts recycling experiment are illustrated in Fig. 19. In this study, the used solid acid catalysts were carefully centrifugal washed with water for 5 -time, following by drying at $105^{\circ} \mathrm{C}$, before the subsequently used. The recycling was achieved with a 6-hour reaction time in conjunction with the optimized reaction condition as catalyst ratio of 0.005:0.04 PC-Im4AILA to PC-Im50BA, 1:3 aqueous to organic phase volume ratio, 3:1 NMP to $\mathrm{H}_{2} \mathrm{O}$ volume ratio, at reaction temperature of $120^{\circ} \mathrm{C}$. The recycling results indicated that the 5 -HMF yield and glucose conversion decreased after each consecutive run. The reduction of the 5-HMF yield was not significant until after the fifth runs where the decrease in the yield was over $20 \%$ which the 5 -HMF yield was about $39.5 \%$ compared to $63.9 \%$ for that of the first run. The production yield of $48.8 \%$ for the third run was still acceptable as the 5 -HMF reduction yield was 
in the range of about $15 \%$. The decrease in glucose conversion and 5 -HMF production yield during recycling test may be attributed to the adsorption and accumulation of humins or cross-polymerized byproducts on the acidic sites within the porous catalyst [49] after several used. Besides, the readily loss of the active Lewis and BrØnsted acidic sites during the reaction, indicated by the characterization result of the spent catalysts from the previous section, was also a major cause for the deactivation of catalytic performance. Interestingly, while the glucose conversion and 5-HMF yield continuingly reduced after consecutive running with the recycled catalysts, greater corresponding 5-HMF selectivity was achieved at the latter cycles. The less reactive catalysts after recycling may deactivate the formation of fructose and the following 5-HMF product, resulting in reduction of the glucose conversion and 5-HMF yield. As a result, a low rate of glucose conversion or fructose transformation may limit the possible polymerization of the correlating products for the undesired byproducts, hence enhancing 5-HMF product selectivity. Moreover, the presence of low BrØnsted acid concentration in the reaction due to the significantly loss of the strong BrØnsted acidic groups during reacting cycle could prevent the formation of the byproducts, since the rate of side reactions that were favorable under the acidic condition (e.g. the direct dehydration of glucose into a reactive fructose intermediate, the rehydration of 5-HMF, or the polymerization of 5-HMF with the sugars, such as glucose, and fructose) could be subsided $[53,55,56,58]$.

\section{Conclusion}

The abundance agro palm oil empty fruit bunch (POFB) waste was the first time utilized as the valueadded biomass-based porous carbon supported Lewis (PC-Im1AILA and PC-Im4AILA) and Brønsted (PCIm50BA) solid acid catalysts for a one-pot conversion of glucose into 5-HMF under a biphasic NMP$\mathrm{H}_{2} \mathrm{O}$ /MIBK system among mild condition. The effective POFB derived porous carbon catalytic support could be conducted by employing the combination of the affordable hydrothermal and carbonization processes. The analysis for the effect of $\mathrm{KOH}$ activating concentration and the operating carbonization temperature revealed more pronounced impact of the activating concentration than that of carbonization temperature on the formation of mesoporous structure. Under the optimized condition whereby applying $1: 2$ biochar to $\mathrm{KOH}$ activating agent at the carbonization temperature of $850^{\circ} \mathrm{C}$, the obtained porous carbon material exposed a multi-scale porous structure with an enhanced specific surface area of $\sim 1600$ $\mathrm{m}^{2} \cdot \mathrm{g}^{-1}$ and the total pore volume of about $1.1 \mathrm{~cm}^{3} \cdot \mathrm{g}^{-1}$. Characterized by the $\mathrm{NH}_{3}-\mathrm{TPD}$, consecutively impregnating the obtained POFB derived porous carbon with $\mathrm{AlCl}_{3}$ and $50 \mathrm{w} / \mathrm{v} \mathrm{H}_{2} \mathrm{SO}_{4}$ led to the strong $\mathrm{Al}_{2} \mathrm{O}_{3}$ and sulfonic acid containing Lewis and BrØnsted solid acid catalysts with a total acidity up to around 2.4 and $13 \mathrm{mmol} . \mathrm{g}^{-1}$, respectively. The influence of operating reaction conditions, involving mixed NMP to $\mathrm{H}_{2} \mathrm{O}$ solvent volume ratio in the aqueous phase, volume ratio of aqueous to organic phase, amount of catalyst loading, and reaction time, as well as, the synergistic impact of mutually using both Lewis and BrØnsted acidic catalysts on the catalytic performance of the 5-HMF production were carefully investigated. The results indicated that increasing the volume ratio of NMP: $\mathrm{H}_{2} \mathrm{O}$ in the aqueous phase, and volume ratio of organic MIBK to aqueous phase, with an appropriated amount of loading catalysts, tended to provide better catalytic performance, generally resulting in higher 5-HMF yield and selectivity. 
Increasing the amount of acid catalysts, especially the BrØnsted acid would promote the glucose conversion to more than $90 \%$, though supporting the formation of byproducts, resulting in quite low 5HMF yield and its selectivity. Prolong the reacting time typically led to the more conversion and 5-HMF production yield. However, running the reaction for too long caused the reduction of 5-HMF production yield and the selectivity, regarding to more possibility of the side reactions. The study of synergistic effect of using dual solid acid catalysts implied that a greater catalytic performance could be achieved by mutually applied both Lewis and BrØnsted solid acid catalysts compared to solely utilizing either Lewis or BrØnsted acidic catalyst. The highest 5-HMF yield, glucose conversion, and 5-HMF selectivity of $63.9 \%$, $100 \%$, and $63.9 \%$, respectively, were accomplished under the optimized condition by employing mixture of 0.005:0.04 g PC-Im4AILA Lewis acid to PC-Im50BA BrØnsted acid catalyst ratio, in the 3:1 volume ratio of mixed NMP to $\mathrm{H}_{2} \mathrm{O}$ solvent, 1:3 bi-phasic aqueous to organic phase volume ratio, under $120^{\circ} \mathrm{C}$, and reacting time of $6 \mathrm{hr}$. In addition, the preliminary assessment of a catalytic recyclability suggested the capability of 3 times catalytic recycling under the optimized reaction condition, where reduction of the 5HMF production yield was less than $20 \%$.

\section{Declarations}

\section{ACKNOWLEDGMENT}

The authors would like to thank the Agricultural Research Development Agency (ARDA), and Kasetsart University Research and Development Institute (KURDI) for the financial support during this project. We are also grateful for the equipment and academic facility by the department of Chemical Engineering, Kasetsart University.

\section{References}

1. Li, H., Bhadury, P.S., Riisager, A., Yang, S.: One-pot transformation of polysaccharides via multicatalytic processes. Catal. Sci. Technol. 4(12), 4138-4168 (2014). doi:10.1039/c4cy00711e

2. Huang, Y.-B., Fu, Y.: Hydrolysis of cellulose to glucose by solid acid catalysts. Green Chem. 15(5) (2013). doi:10.1039/c3gc40136g

3. Gai, C., Zhang, F., Guo, Y., Peng, N., Liu, T., Lang, Q., Xia, Y., Liu, Z.: Hydrochar-Supported, in SituGenerated Nickel Nanoparticles for Sorption-Enhanced Catalytic Gasification of Sewage Sludge. ACS Sustainable Chemistry \& Engineering. 5(9), 7613-7622 (2017).

doi:10.1021/acssuschemeng.7b00924

4. Dai, J., Zhang, R., Ge, W., Xie, A., Chang, Z., Tian, S., Zhou, Z., Yan, Y.: 3D macroscopic superhydrophobic magnetic porous carbon aerogel converted from biorenewable popcorn for selective oil-water separation. Materials \& Design. 139, 122-131 (2018). doi:10.1016/j.matdes.2017.11.001

5. Al Arni, S.: Comparison of slow and fast pyrolysis for converting biomass into fuel. Renewable Energy. 124, 197-201 (2018). doi:10.1016/j.renene.2017.04.060 
6. Pumrod, S., Kaewchada, A., Roddecha, S., Jaree, A.: 5-HMF production from glucose using ion exchange resin and alumina as a dual catalyst in a biphasic system. RSC Advances. 10(16), 94929498 (2020). doi:10.1039/c9ra09997b

7. Pagán-Torres, Y.J., Wang, T., Gallo, J.M.R., Shanks, B.H., Dumesic, J.A.: Production of 5Hydroxymethylfurfural from Glucose Using a Combination of Lewis and Brønsted Acid Catalysts in Water in a Biphasic Reactor with an Alkylphenol Solvent. ACS Catalysis. 2(6), 930-934 (2012). doi:10.1021/cs300192z

8. Rusanen, A., Lahti, R., Lappalainen, K., Kärkkäinen, J., Hu, T., Romar, H., Lassi, U.: Catalytic conversion of glucose to 5-hydroxymethylfurfural over biomass-based activated carbon catalyst. Catal. Today. 357, 94-101 (2020). doi:10.1016/j.cattod.2019.02.040

9. Saha, B., Abu-Omar, M.M.: Advances in 5-hydroxymethylfurfural production from biomass in biphasic solvents. Green Chem. 16(1), 24-38 (2014). doi:10.1039/c3gc41324a

10. Chen, D., Liang, F., Feng, D., Xian, M., Zhang, H., Liu, H., Du, F.: An efficient route from reproducible glucose to 5 -hydroxymethylfurfural catalyzed by porous coordination polymer heterogeneous catalysts. Chem. Eng. J. 300, 177-184 (2016). doi:10.1016/j.cej.2016.04.039

11. Zhang, L., Xi, G., Chen, Z., Qi, Z., Wang, X.: Enhanced formation of 5-HMF from glucose using a highly selective and stable SAPO-34 catalyst. Chem. Eng. J. 307, 877-883 (2017). doi:10.1016/j.cej.2016.09.003

12. Najafi Chermahini, A., Shahangi, F., Dabbagh, H.A., Saraji, M.: Production of 5-hydroxymethylfurfural from fructose using a spherically fibrous KCC-1 silica catalyst. RSC Advances. 6(40), 33804-33810 (2016). doi:10.1039/c6ra03382b

13. Hafizi, H., Najafi Chermahini, A., Saraji, M., Mohammadnezhad, G.: The catalytic conversion of fructose into 5-hydroxymethylfurfural over acid-functionalized KIT-6, an ordered mesoporous silica. Chem. Eng. J. 294, 380-388 (2016). doi:10.1016/j.cej.2016.02.082

14. Ordomsky, V.V., van der Schaaf, J., Schouten, J.C., Nijhuis, T.A.: The effect of solvent addition on fructose dehydration to 5-hydroxymethylfurfural in biphasic system over zeolites. J. Catal. 287, 6875 (2012). doi:10.1016/j.jcat.2011.12.002

15. Sampath, G., Kannan, S.: Fructose dehydration to 5-hydroxymethylfurfural: Remarkable solvent influence on recyclability of Amberlyst- 15 catalyst and regeneration studies. Catal. Commun. 37, 4144 (2013). doi:10.1016/j.catcom.2013.03.021

16. Yang, L., Yan, X., Xu, S., Chen, H., Xia, H., Zuo, S.: One-pot synthesis of 5-hydroxymethylfurfural from carbohydrates using an inexpensive FePO4 catalyst. RSC Advances. 5(26), 19900-19906 (2015). doi:10.1039/c4ra16145a

17. Matthiesen, J., Hoff, T., Liu, C., Pueschel, C., Rao, R., Tessonnier, J.-P.: Functional carbons and carbon nanohybrids for the catalytic conversion of biomass to renewable chemicals in the condensed phase. Chin. J. Catal. 35(6), 842-855 (2014). doi:10.1016/s1872-2067(14)60122-4

18. Prati, L., Bergna, D., Villa, A., Spontoni, P., Bianchi, C.L., Hu, T., Romar, H., Lassi, U.: Carbons from second generation biomass as sustainable supports for catalytic systems. Catal. Today. 301, 239- 
243 (2018). doi:10.1016/j.cattod.2017.03.007

19. Danish, M., Ahmad, T.: A review on utilization of wood biomass as a sustainable precursor for activated carbon production and application. Renew. Sustain. Energy Rev. 87, 1-21 (2018). doi:10.1016/j.rser.2018.02.003

20. González-García, P.: Activated carbon from lignocellulosics precursors: A review of the synthesis methods, characterization techniques and applications. Renew. Sustain. Energy Rev. 82, 1393-1414 (2018). doi:10.1016/j.rser.2017.04.117

21. Mäkelä, E., Lahti, R., Jaatinen, S., Romar, H., Hu, T., Puurunen, R.L., Lassi, U., Karinen, R.: Study of Ni, Pt, and Ru Catalysts on Wood-based Activated Carbon Supports and their Activity in Furfural Conversion to 2-Methylfuran. ChemCatChem. 10(15), 3269-3283 (2018). doi:10.1002/cctc. 201800263

22. Liu, X., Shen, B., Yuan, P., Patel, D., Wu, C.: Production of carbon nanotubes (CNTs) from thermochemical conversion of waste plastics using Ni/anodic aluminum oxide (AAO) template catalyst. Energy Procedia. 142, 525-530 (2017). doi:10.1016/j.egypro.2017.12.082

23. Chiang, C.L., Lin, K.S., Yu, S.H.: Improvement of dimethyl carbonate formation via methanol carbonation over vanadium-doped $\mathrm{Cu}-\mathrm{Ni} / \mathrm{AC}$ catalyst. J. Taiwan Inst. Chem. Eng. 98, 132-149 (2019). doi:10.1016/j.jtice.2018.08.001

24. Xu, S., Pan, D., Hu, F., Wu, Y., Wang, H., Chen, Y., Yuan, H., Gao, L., Xiao, G.: Highly efficient Cr/ $\beta$ zeolite catalyst for conversion of carbohydrates into 5-hydroxymethylfurfural: Characterization and performance. Fuel Processing Technology 190, 38-46: (2019). doi:10.1016/j.fuproc.2019.03.012

25. Liu, T., Li, Z., Li, W., Shi, C., Wang, Y.: Preparation and characterization of biomass carbon-based solid acid catalyst for the esterification of oleic acid with methanol. Bioresour. Technol. 133, 618-621 (2013). doi:10.1016/j.biortech.2013.01.163

26. Zhang, M., Sun, A., Meng, Y., Wang, L., Jiang, H., Li, G.: Catalytic Performance of Biomass CarbonBased Solid Acid Catalyst for Esterification of Free Fatty Acids in Waste Cooking Oil. Catal. Surv. Asia. 19(2), 61-67 (2014). doi:10.1007/s10563-014-9182-y

27. Thushari, I., Babel, S.: Preparation of solid acid catalysts from waste biomass and their application for microwave-assisted biodiesel production from waste palm oil. Waste Manag Res. 36(8), 719-728 (2018). doi:10.1177/0734242X18789821

28. Singh, R.P., Ibrahim, M.H., Esa, N., Iliyana, M.S.: Composting of waste from palm oil mill: a sustainable waste management practice. Reviews in Environmental Science and Bio/Technology. 9(4), 331-344 (2010). doi:10.1007/s11157-010-9199-2

29. Iskandar, M.J., Baharum, A., Anuar, F.H., Othaman, R.: Palm oil industry in South East Asia and the effluent treatment technology-A review. Environmental Technology \& Innovation. 9, 169-185 (2018). doi:10.1016/j.eti.2017.11.003

30. Putra, M.D., Ristianingsih, Y., Jelita, R., Irawan, C., Nata, I.F.: Potential waste from palm empty fruit bunches and eggshells as a heterogeneous catalyst for biodiesel production. RSC Advances. 7(87), 55547-55554 (2017). doi:10.1039/c7ra11031f 
31. Thushari, I., Babel, S.: Activity of Carbon-Based Solid Acid Catalyst Derived from Palm Empty Fruit Bunch for Esterification of Palmitic Acid. Environment and Natural Resources Journal. 17(1), 54-62 (2019). doi:10.32526/ennrj.17.1.2019.06

32. Wong, W.Y., Lim, S., Pang, Y.L., Shuit, S.H., Chen, W.H., Lee, K.T.: Synthesis of renewable heterogeneous acid catalyst from oil palm empty fruit bunch for glycerol-free biodiesel production. Sci. Total Environ. 727, 138534 (2020). doi:10.1016/j.scitotenv.2020.138534

33. Ahmad, N., Ibrahim, N., Ali, U.F.M., Yusuf, S.Y., Ridwan, F.M.: Carbon-supported CuO Catalyst Prepared from Oil Palm Empty Fruit Bunch (EFB) for Low-temperature No Removal. Procedia Eng. 148, 823829 (2016). doi:10.1016/j.proeng.2016.06.623

34. Fanani, Z., Rohendi, D., Dewi, T.K., Dzulfikar, M.A., Said, M.: Preparation and Characterization of Catalyst Cr/Activated Carbonfrom Palm Empty Fruit Bunch. Indonesia Journal of Fundamental and Applied Chemistry. 1, 35-41 (2016). doi:10.24845/ijfac.v1.i2.35

35. Kingsakklang, S., Roddecha, S., Sriariyana, M.: The Interconnected Open-Channel Highly Porous Carbon Material Derived from Pineapple Leaf Fibers as a Sustainable Electrode Material for Electrochemical Energy Storage Devices. Key Eng. Mater. 798, 97-104 (2019). doi:10.4028/www.scientific.net/KEM.798.97

36. Ferreira, A.R.O., Silvestre-Albero, J., Maier, M.E., Ricardo, N.M.P.S., Cavalcante, C.L., Luna, F.M.T.: Sulfonated activated carbons as potential catalysts for biolubricant synthesis. Molecular Catalysis 488 (2020). doi:10.1016/j.mcat.2020.110888

37. Fonseca, J.M., Spessato, L., Cazetta, A.L., Bedin, K.C., Melo, S.A.R., Souza, F.L., Almeida, V.C.: Optimization of sulfonation process for the development of carbon-based catalyst from crambe meal via response surface methodology. Energy Convers. Manag. 217 (2020). doi:10.1016/j.enconman.2020.112975

38. Kumar, N., Biswas, K.: Cryomilling: An environment friendly approach of preparation large quantity ultra refined pure aluminium nanoparticles. Journal of Materials Research and Technology. 8(1), 6374 (2019). doi:10.1016/j.jmrt.2017.05.017

39. Lu, W., Iwasa, Y., Ou, Y., Jinno, D., Kamiyama, S., Petersen, P.M., Ou, H.: Effective optimization of surface passivation on porous silicon carbide using atomic layer deposited Al203. RSC Advances. 7(14), 8090-8097 (2017). doi:10.1039/c6ra27281a

40. Shanthi, P.M., Hanumantha, P.J., Ramalinga, K., Gattu, B., Datta, M.K., Kumta, P.N.: Sulfonic Acid Based Complex Framework Materials (CFM): Nanostructured Polysulfide Immobilization Systems for Rechargeable Lithium-Sulfur Battery. Journal of The Electrochemical Society. 166(10), A1827A1835 (2019). doi:10.1149/2.0251910jes

41. Shimada, S., Hiroi, T., Ida, T., Mizuno, M., Endo, K., Kurmaev, E.Z., Moewes, A.: X-ray photoelectron and carbon Ka emission measurements and calculations of $\mathrm{O}-, \mathrm{CO}-\mathrm{N}-$, and S-containing substances. J. Polym. Sci., Part B: Polym. Phys. 45(2), 162-172 (2007). doi:10.1002/polb.20991

42. Zhang, T., Li, W., Jin, Y., Ou, W.: Synthesis of sulfonated chitosan-derived carbon-based catalysts and their applications in the production of 5-hydroxymethylfurfural. Int J Biol Macromol. 157, 368-376 
(2020). doi:10.1016/j.ijbiomac.2020.04.148

43. Figueiredo, J.L., Pereira, M.F.R.: The role of surface chemistry in catalysis with carbons. Catal. Today. 150(1-2), 2-7 (2010). doi:10.1016/j.cattod.2009.04.010

44. Shu, Q., Gao, J., Nawaz, Z., Liao, Y., Wang, D., Wang, J.: Synthesis of biodiesel from waste vegetable oil with large amounts of free fatty acids using a carbon-based solid acid catalyst. Appl. Energy. 87(8), 2589-2596 (2010). doi:10.1016/j.apenergy.2010.03.024

45. Pang, Q., Wang, L., Yang, H., Jia, L., Pan, X., Qiu, C.: Cellulose-derived carbon bearing $-\mathrm{Cl}$ and $-\mathrm{SO} \mathrm{H}$ groups as a highly selective catalyst for the hydrolysis of cellulose to glucose. RSC Adv. 4(78), 41212-41218 (2014). doi:10.1039/c4ra05520a

46. Zhang, T., Li, W., Xin, H., Jin, L., Liu, Q.: Production of HMF from glucose using an Al3+-promoted acidic phenol-formaldehyde resin catalyst. Catal. Commun. 124, 56-61 (2019). doi:10.1016/j.catcom.2019.03.001

47. Zhang, T., Li, W., An, S., Huang, F., Li, X., Liu, J., Pei, G., Liu, Q.: Efficient transformation of corn stover to furfural using p-hydroxybenzenesulfonic acid-formaldehyde resin solid acid. Bioresour. Technol. 264, 261-267 (2018). doi:10.1016/j.biortech.2018.05.081

48. Wang, J., Zhang, Y., Wang, Y., Zhu, L., Cui, H., Yi, W.: Catalytic fructose dehydration to 5hydroxymethylfurfural over sulfonated carbons with hierarchically ordered pores. Journal of Fuel Chemistry and Technology. 44(11), 1341-1348 (2016). doi:10.1016/s1872-5813(16)30058-5

49. Deng, A., Lin, Q., Yan, Y., Li, H., Ren, J., Liu, C., Sun, R.: A feasible process for furfural production from the pre-hydrolysis liquor of corncob via biochar catalysts in a new biphasic system. Bioresour. Technol. 216, 754-760 (2016). doi:10.1016/j.biortech.2016.06.002

50. Farabi, M.S.A., Ibrahim, M.L., Rashid, U., Taufiq-Yap, Y.H.: Esterification of palm fatty acid distillate using sulfonated carbon-based catalyst derived from palm kernel shell and bamboo. Energy Convers. Manag.. 181, 562-570 (2019). doi:10.1016/j.enconman.2018.12.033

51. Abou-Yousef, H., Hassan, E.B.: Efficient utilization of aqueous phase bio-oil to furan derivatives through extraction and sugars conversion in acid-catalyzed biphasic system. Fuel. 137, 115-121 (2014). doi:10.1016/j.fuel.2014.07.067

52. Zhou, C., Zhao, J., Yagoub, A.E.A., Ma, H., Yu, X., Hu, J., Bao, X., Liu, S.: Conversion of glucose into 5hydroxymethylfurfural in different solvents and catalysts: Reaction kinetics and mechanism. Egyptian J Petroleum. 26(2), 477-487 (2017). doi:10.1016/j.ejpe.2016.07.005

53. Yang, G., Pidko, E.A., Hensen, E.J.M.: Mechanism of Brønsted acid-catalyzed conversion of carbohydrates. J. Catal. 295, 122-132 (2012). doi:10.1016/j.jcat.2012.08.002

54. Yang, L., Tsilomelekis, G., Caratzoulas, S., Vlachos, D.G.: Mechanism of Bronsted acid-catalyzed glucose dehydration. ChemSusChem. 8(8), 1334-1341 (2015). doi:10.1002/cssc.201403264

55. Badgujar, K.C., Wilson, L.D., Bhanage, B.M.: Recent advances for sustainable production of levulinic acid in ionic liquids from biomass: Current scenario, opportunities and challenges. Renew. Sustain. Energy Rev. 102, 266-284 (2019). doi:10.1016/j.rser.2018.12.007 
56. Hu, X., Li, C.-Z.: Levulinic esters from the acid-catalysed reactions of sugars and alcohols as part of a bio-refinery. Green Chem. 13(7) (2011). doi:10.1039/c1gc15272f

57. Li, X., Zhang, Y., Xia, Q., Liu, X., Peng, K., Yang, S., Wang, Y.: Acid-Free Conversion of Cellulose to 5(Hydroxymethyl)furfural Catalyzed by Hot Seawater. Industrial \& Engineering Chemistry Research. 57(10), 3545-3553 (2018). doi:10.1021/acs.iecr.8b00443

58. Dee, S.J., Bell, A.T.: A study of the acid-catalyzed hydrolysis of cellulose dissolved in ionic liquids and the factors influencing the dehydration of glucose and the formation of humins. ChemSusChem. 4(8), 1166-1173 (2011). doi:10.1002/cssc.201000426

\section{Figures}

RO<smiles>O=Cc1ccc(CO)o1</smiles>

5-Alkoxymethylfurfural 2<smiles>O=C(O)c1ccc(C(=O)O)o1</smiles>

\section{2,5-Furandicarboxylic acid 3}<smiles>O=C(O)c1ccc(CO)o1</smiles>

\section{5-Hydroxymethylfuroic acid 4}<smiles>OCc1ccc(CO)o1</smiles>

2,5-Bishydroxymethylfuran 5
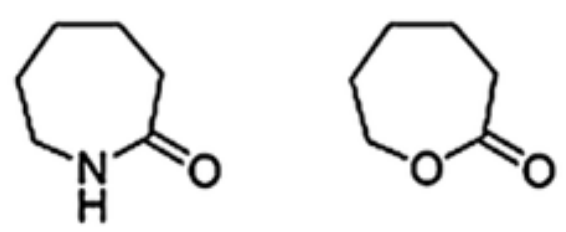

Caprolactam 11 Caprolactone 12
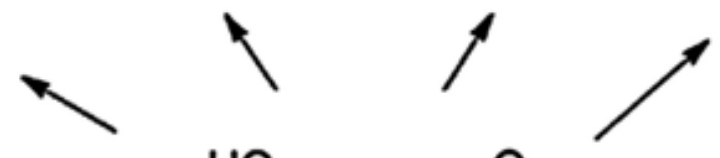<smiles>OCCCCCCCO</smiles>

1,6-Hexanediol 10<smiles>O=Cc1ccc(CO)o1</smiles>

HMF 1<smiles>C[12CH2]C(=O)CCCCCC(=O)O</smiles>

Adipic acid 9
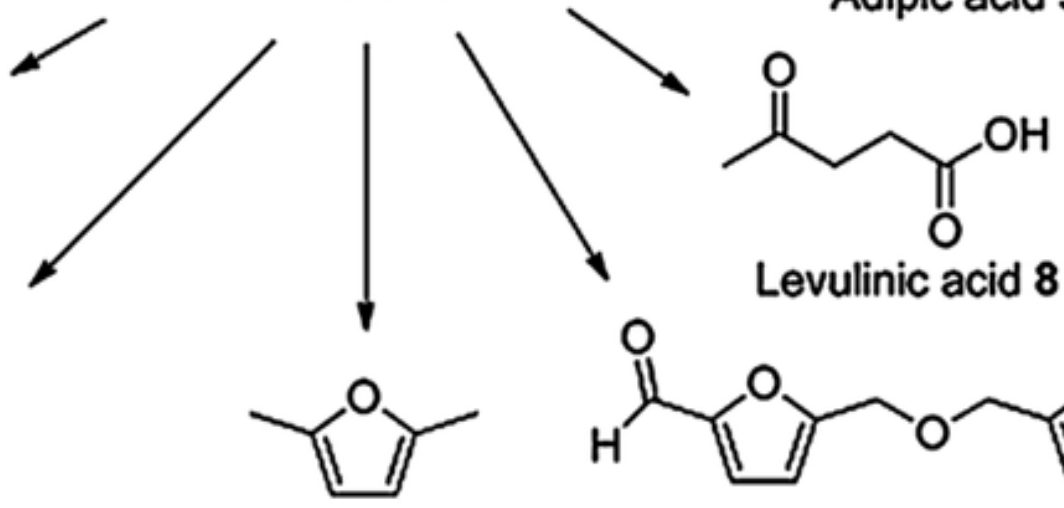

Levulinic acid 8<smiles>O=Cc1ccc(COCc2ccc(C=O)o2)o1</smiles>

2,5-Dimethylfuran 6

Figure 1

5-HMF applications [6] 


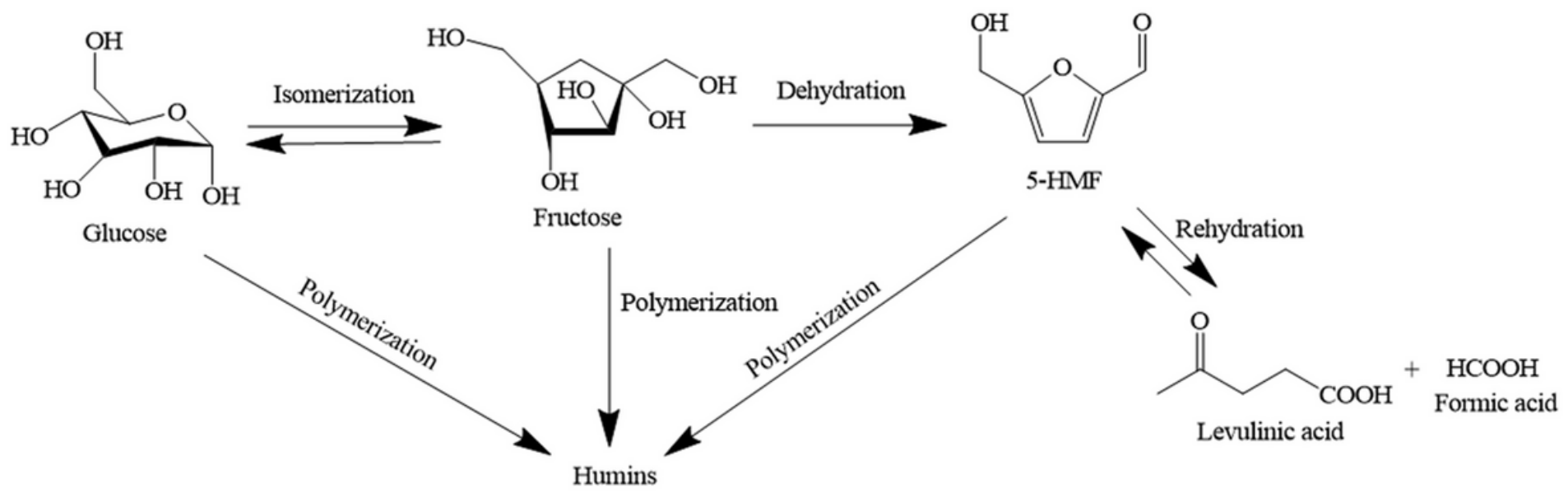

Figure 2

Reaction conversion of glucose to 5-HMF [6]

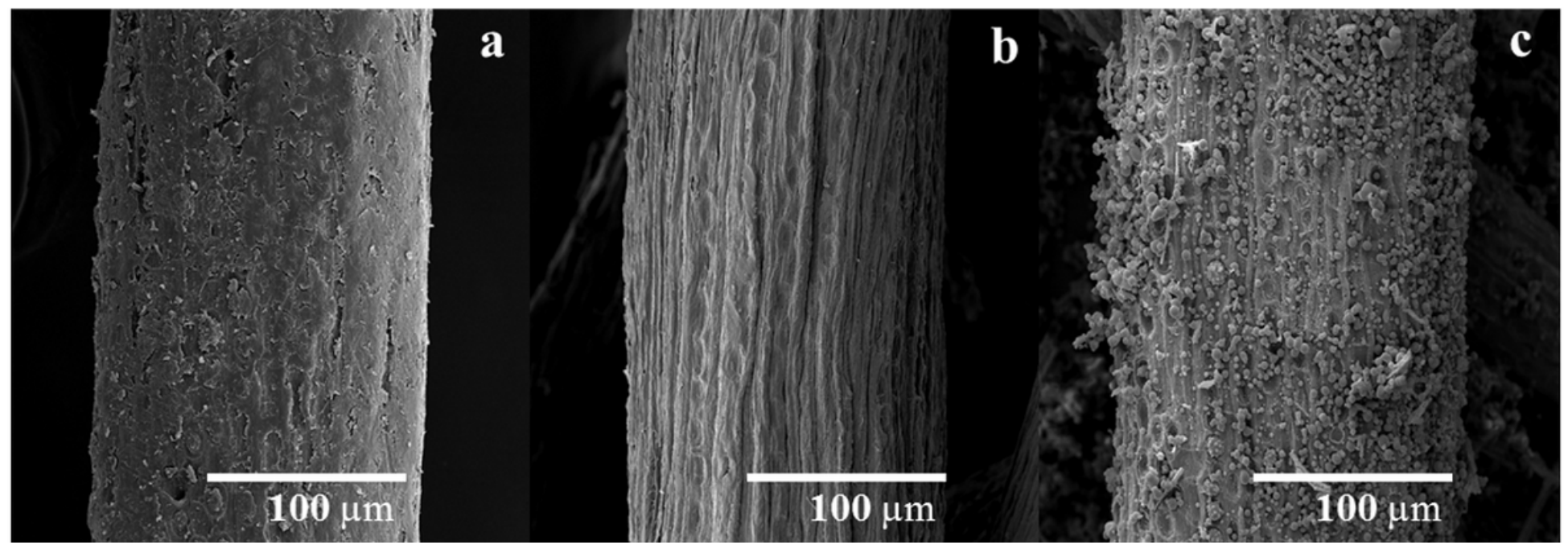

\section{Figure 3}

SEM images of palm oil empty fruit bunches (POFB): a) dried POFB, b) $\mathrm{NaOH}$ pretreated POFB, c) biochar 


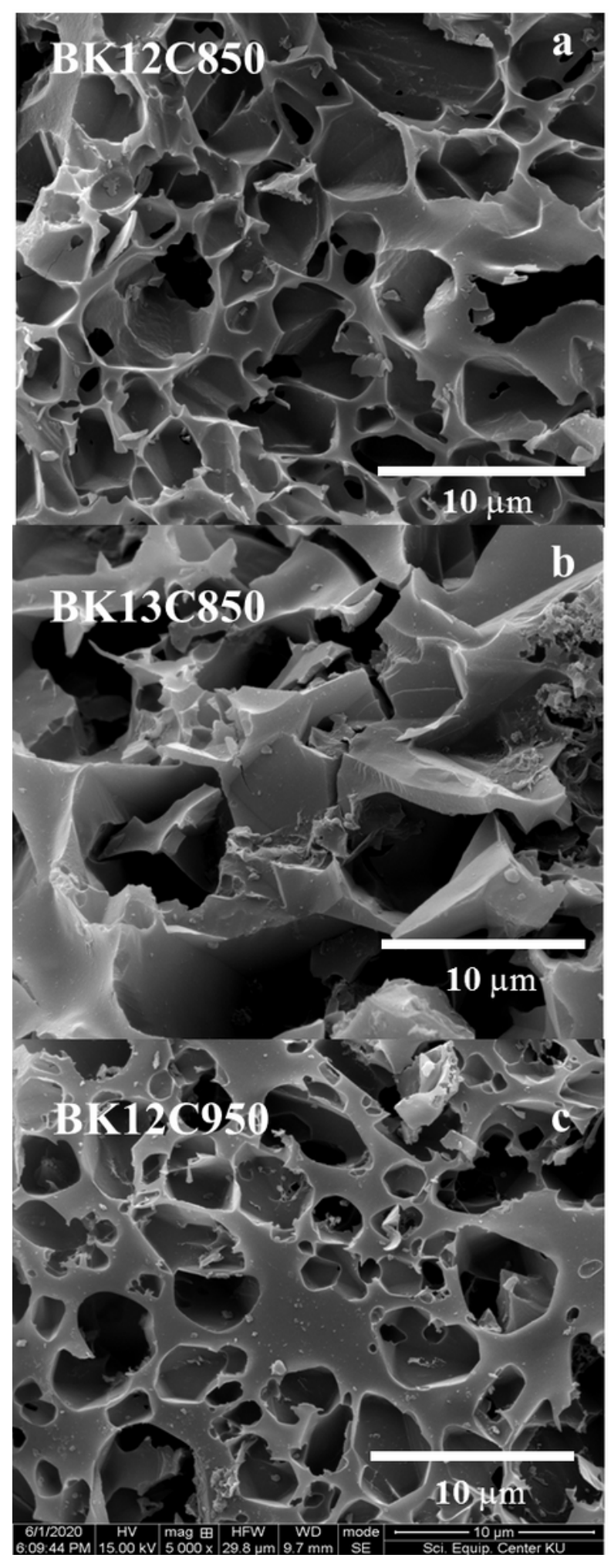

Figure 4

SEM images of the obtained porous carbon material prepared under carbonization temperature of $850^{\circ} \mathrm{C}$ at different $\mathrm{KOH}$ activation concentrations: a) biochar to $\mathrm{KOH}$ as $1: 2$, b) biochar to $\mathrm{KOH}$ as 1:3, c) biochar to $\mathrm{KOH}$ as $1: 2$ but undergone under carbonization temperature of $950^{\circ} \mathrm{C}$. 


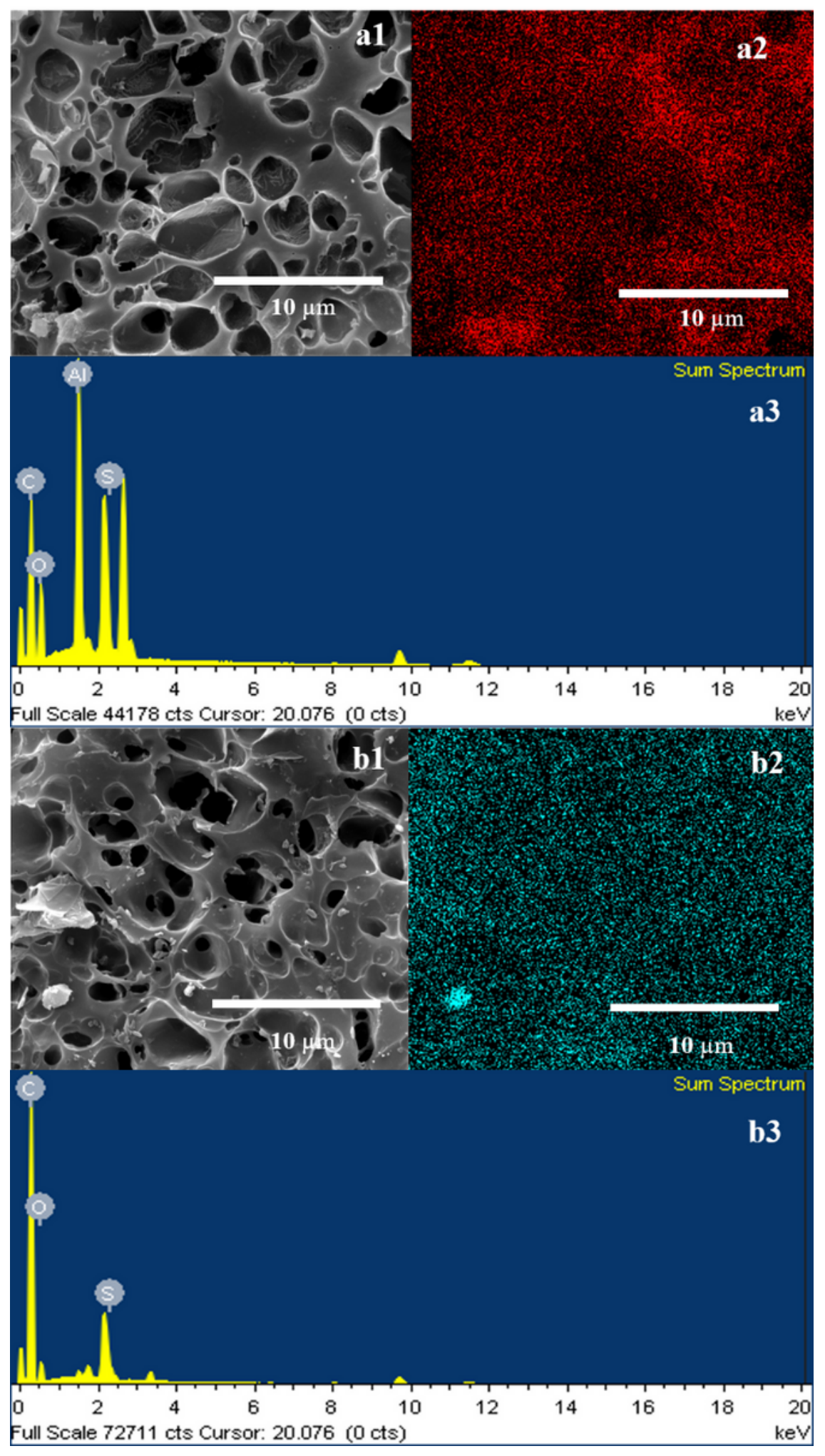

\section{Figure 5}

SEM images of the acid functionalized POFB derived porous carbon material: a1) PC-Im4AILA, b1) PCIm50BA, their active elemental analysis mapping of a2) aluminium, b2) sulfur, and their corresponding energy dispersive spectroscopic (EDS) spectra of a3) PC-Im4AILA, b3) PC-Im50BA 

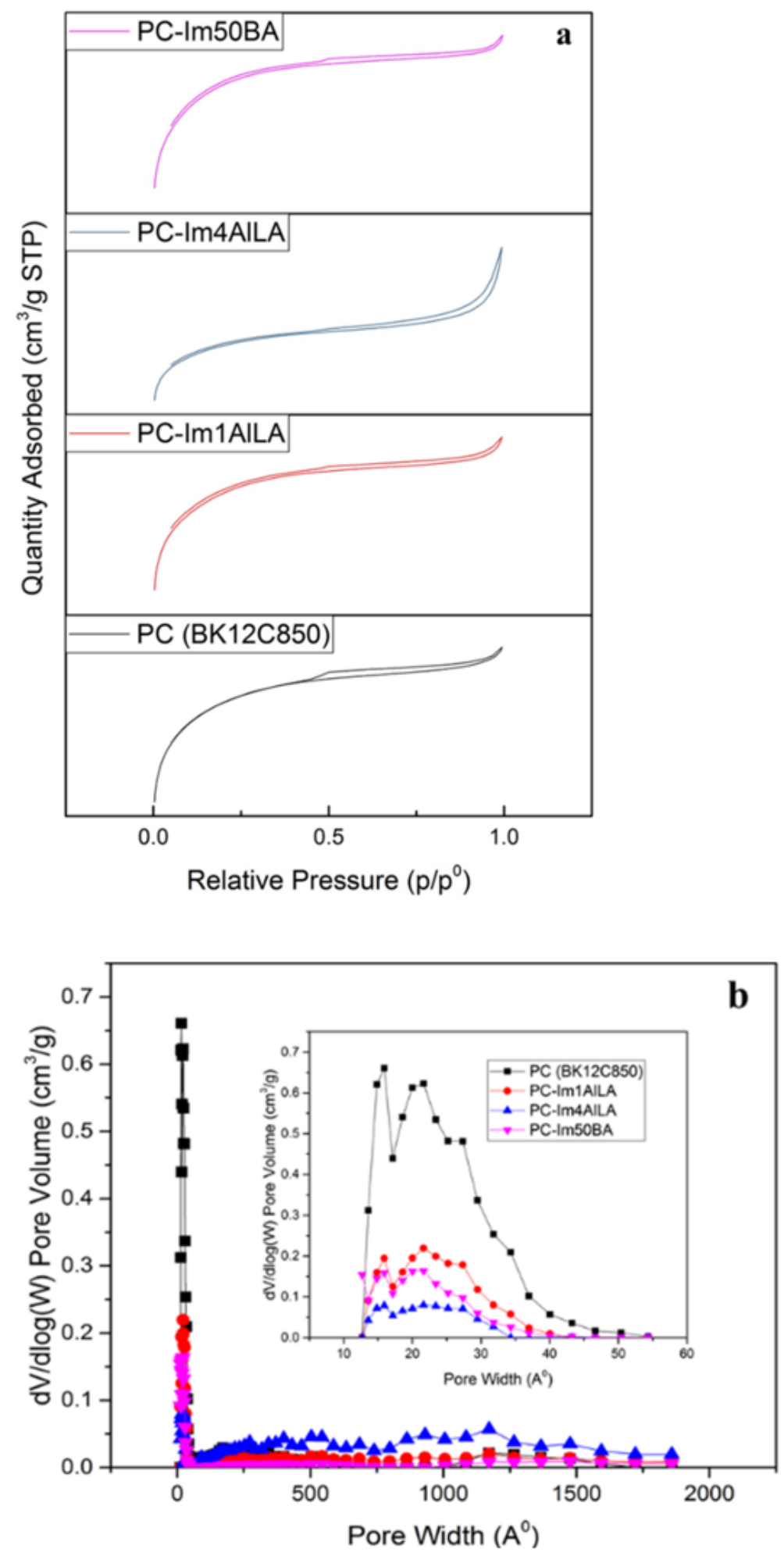

\section{Figure 6}

The porous morphology analysis of the prepared porous carbon support and the solid acid catalyst samples by N2 adsorption technique: a) N2 adsorption-desorption isotherms and b) pore size distribution 


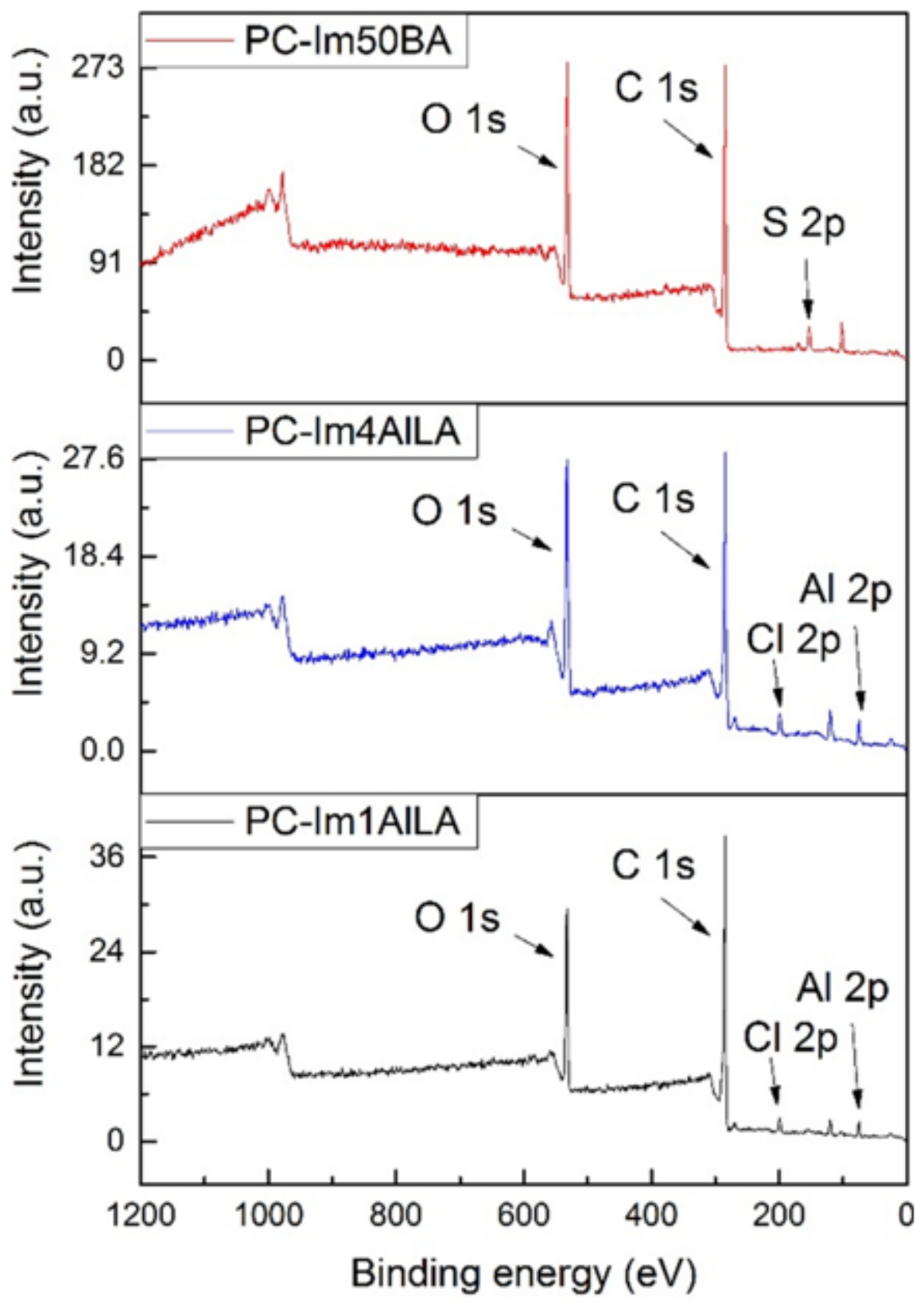

Figure 7

XPS survey spectra of PC-Im50BA, PC-Im4AILA, and PC-Im1AILA 

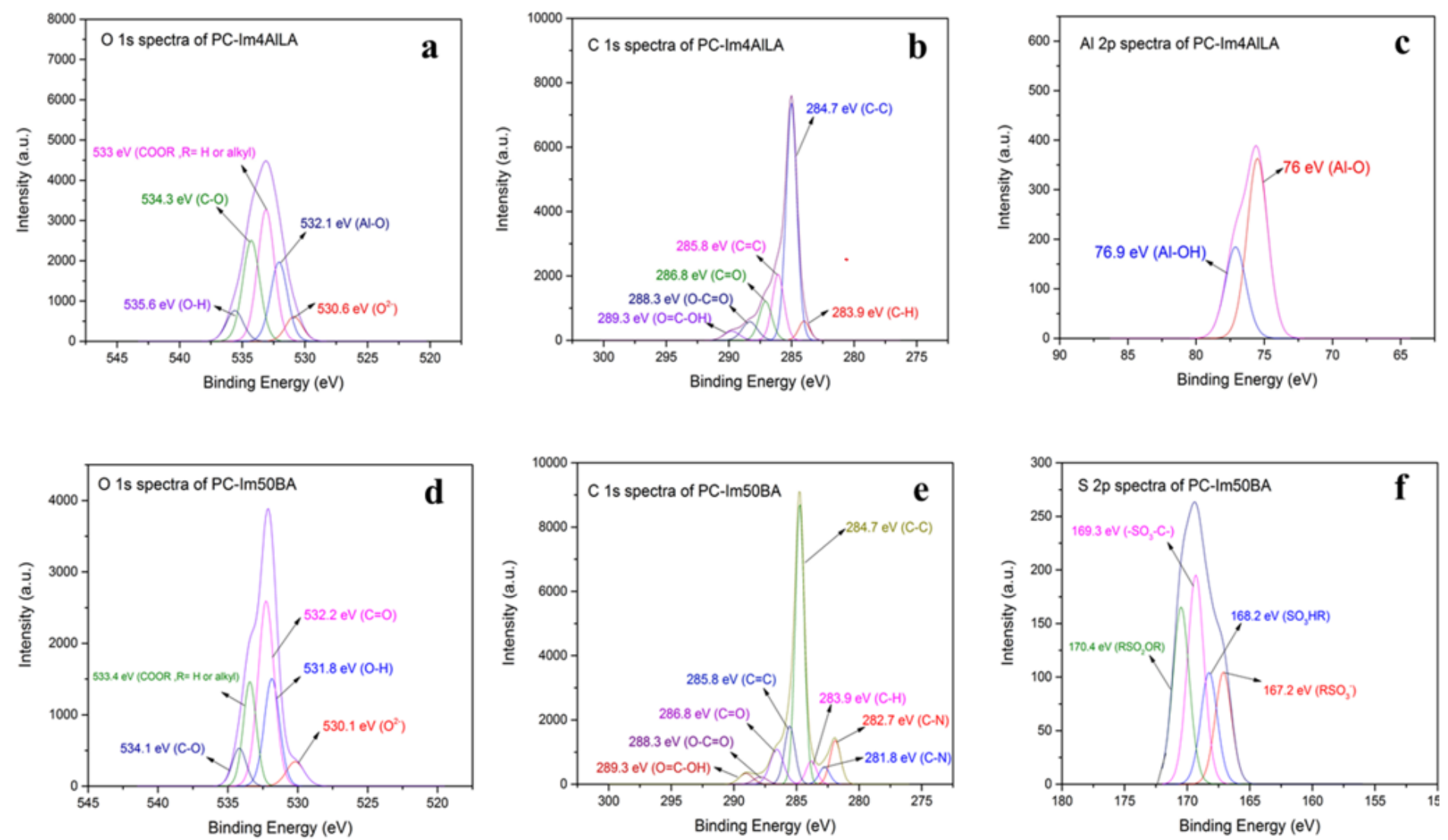

\section{Figure 8}

Deconvoluted high-resolution XPS spectra for PC-Im4AILA: a) 01s, b) C1s and c) Al2p, and for PCIm50BA: d) 01s, e) C1s and f) S2p. 


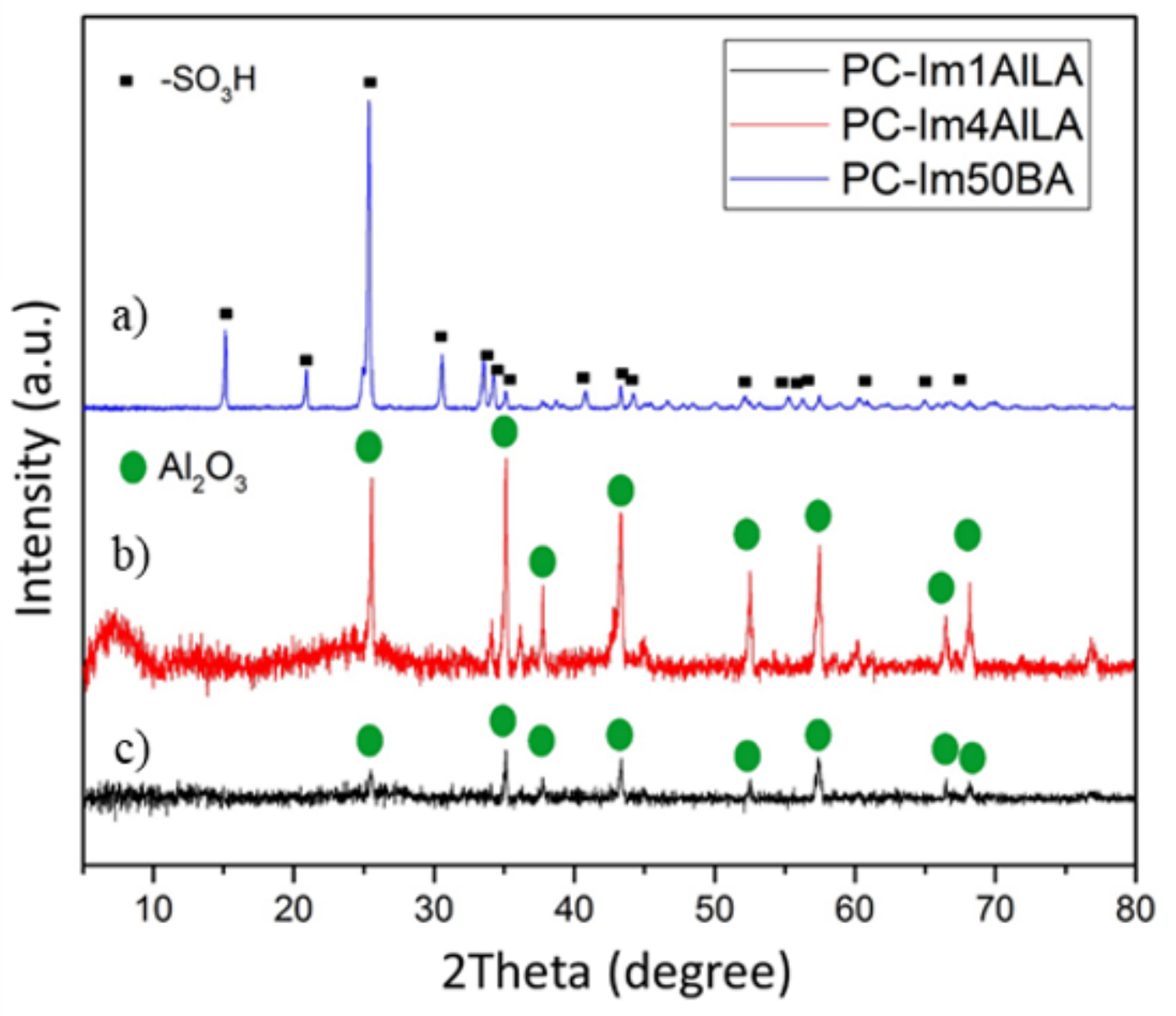

Figure 9

XRD pattern of a) PC-Im50BA, b) PC-Im4AILA and c) PC-Im1AILA 


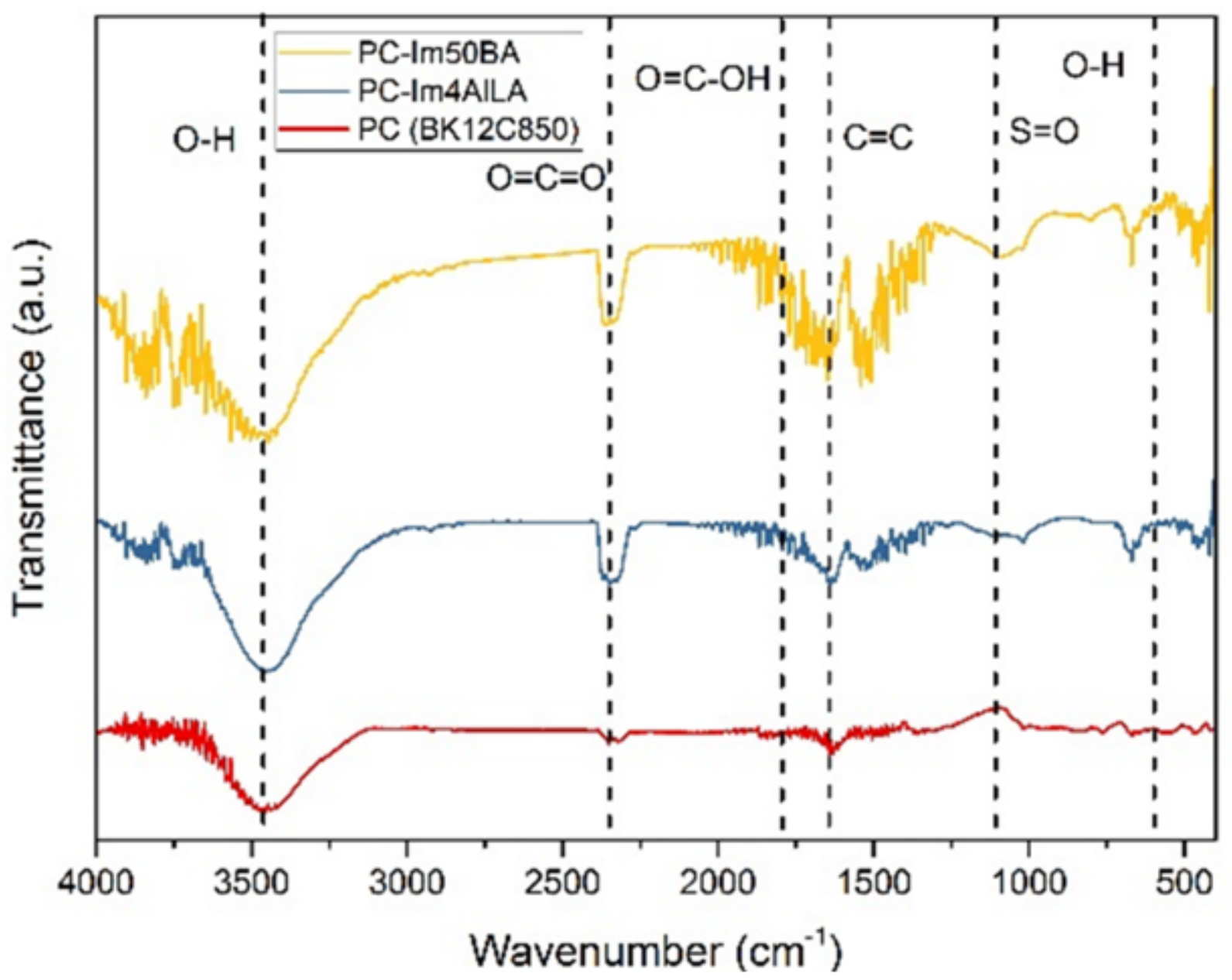

Figure 10

FTIR spectra of porous carbon support (BK12C850), PC-Im4AILA, and PC-Im50BA 


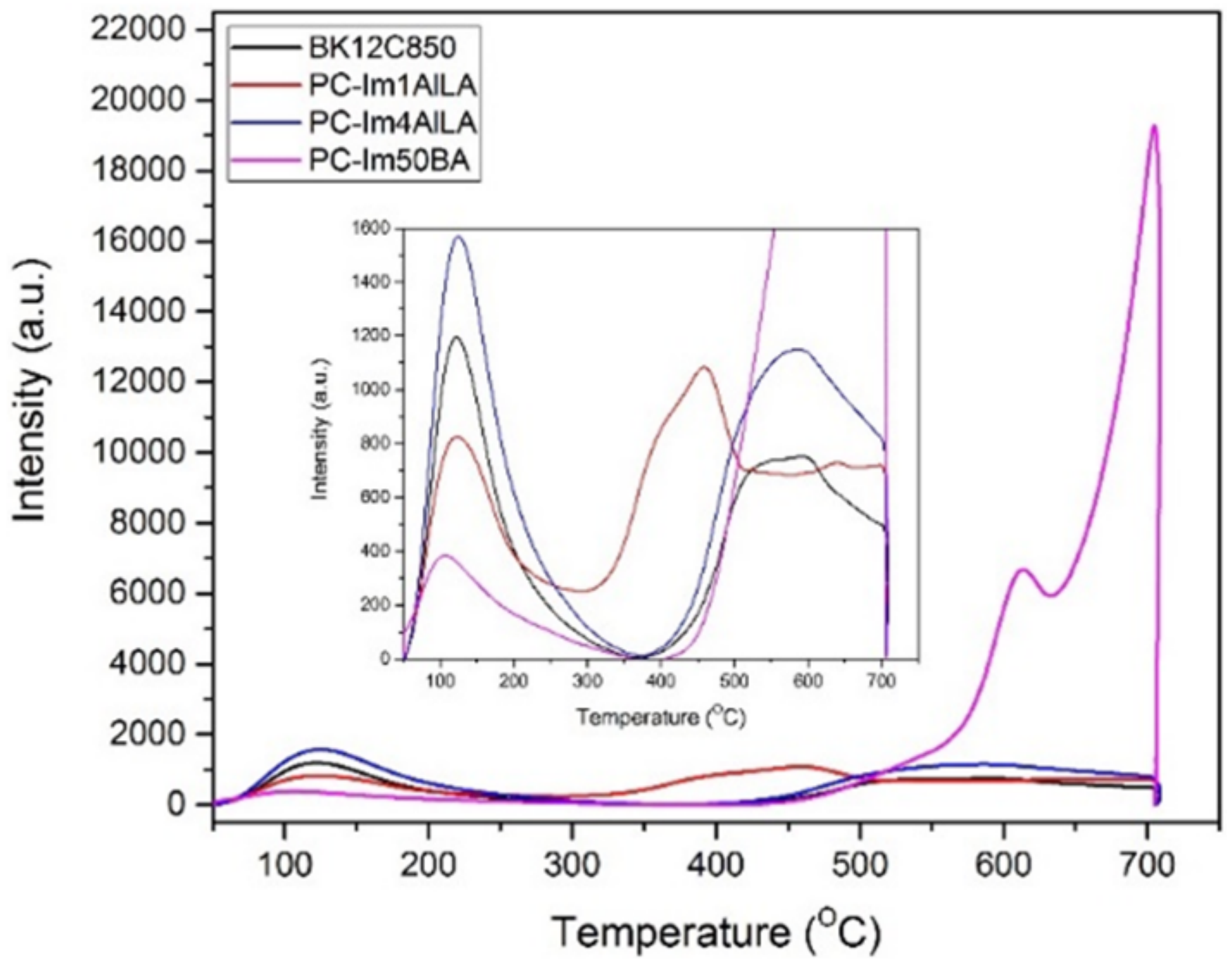

Figure 11

NH3-TPD analysis of porous carbon support (BK12C850), PC-Im1AlLA, PC-Im4AILA, and PC-Im50BA 


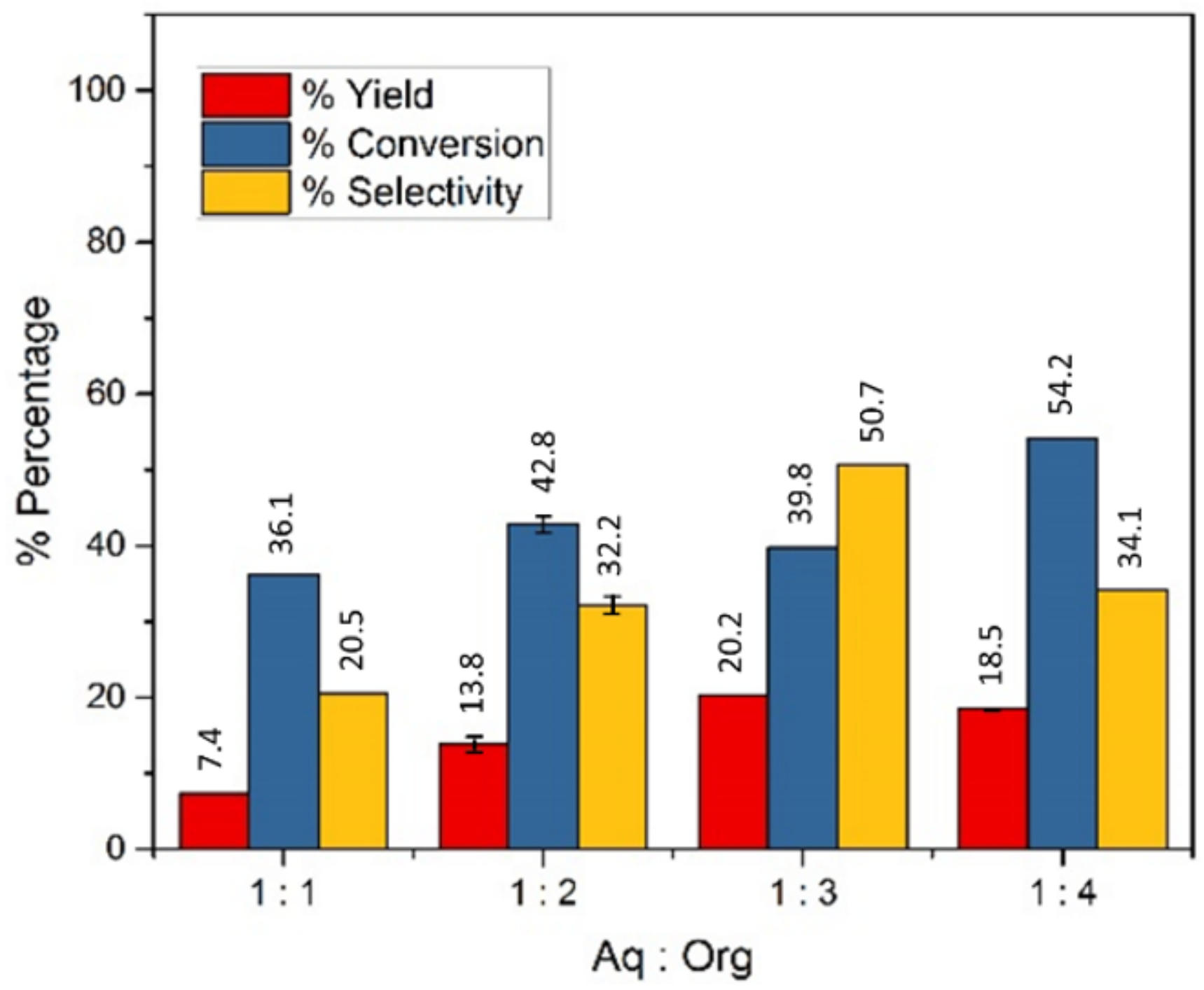

Figure 12

Effect of aqueous to organic phase ratio (reaction conditions: $0.01 \mathrm{~g}$ of glucose, NMP:H2O volume ratio = $1: 1,0.05 \mathrm{~g}$ of $\mathrm{NaCl}, 0.005 \mathrm{~g}$ of PC-Im4AILA, $0.04 \mathrm{~g}$ of PC-Im50BA, reaction temperature of $120^{\circ} \mathrm{C}$ and reaction time of $60 \mathrm{~min}$. 


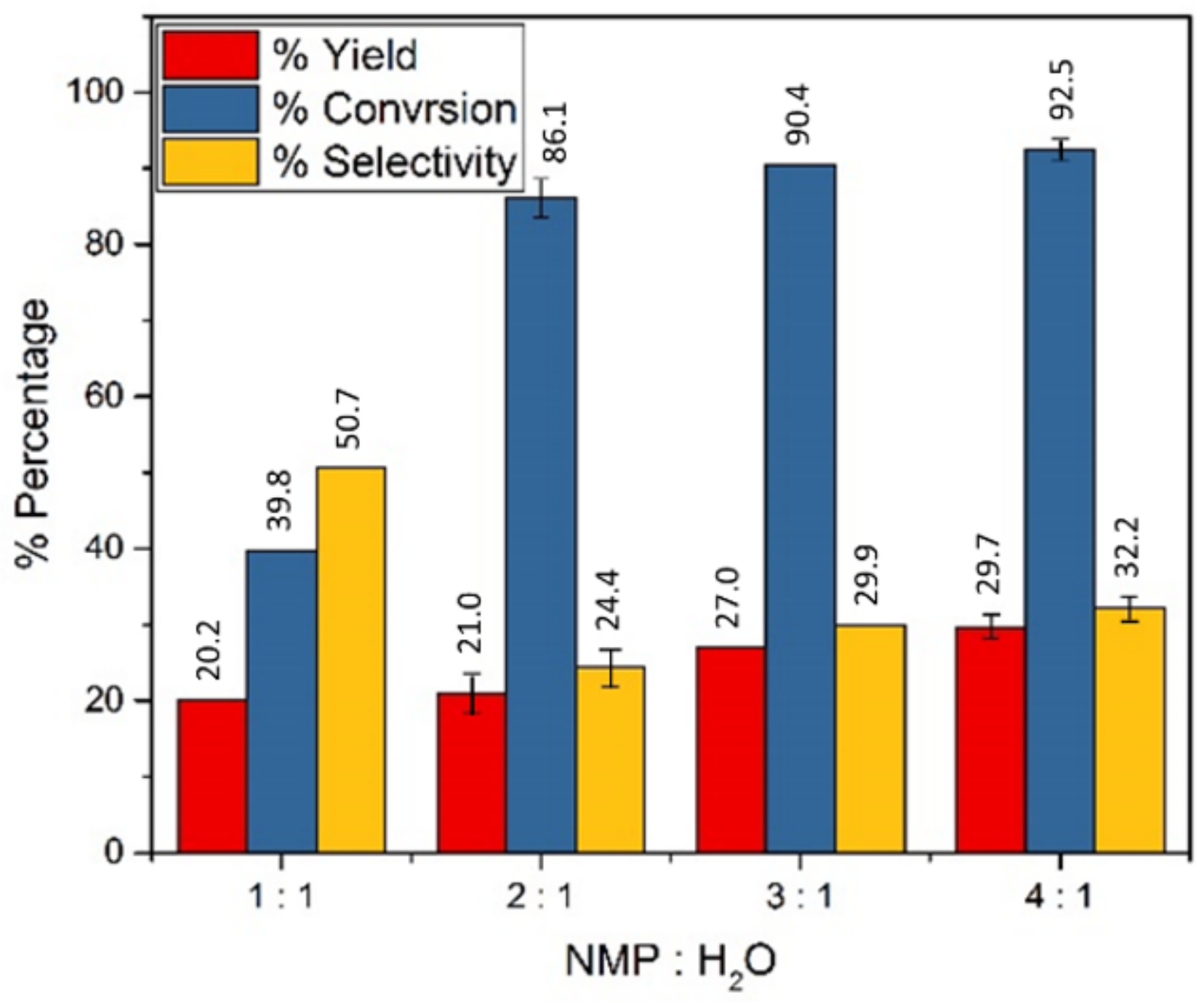

Figure 13

Effect of NMP to $\mathrm{H} 2 \mathrm{O}$ volume ratio (reaction conditions: $0.01 \mathrm{~g}$ of glucose, aqueous to organic phase volume $=1: 3,0.05 \mathrm{~g}$ of $\mathrm{NaCl}, 0.005 \mathrm{~g}$ of PC-Im4AILA, $0.04 \mathrm{~g}$ of PC-Im50BA, reaction temperature of 120 ${ }^{\circ} \mathrm{C}$, and reaction time of $60 \mathrm{~min}$ 


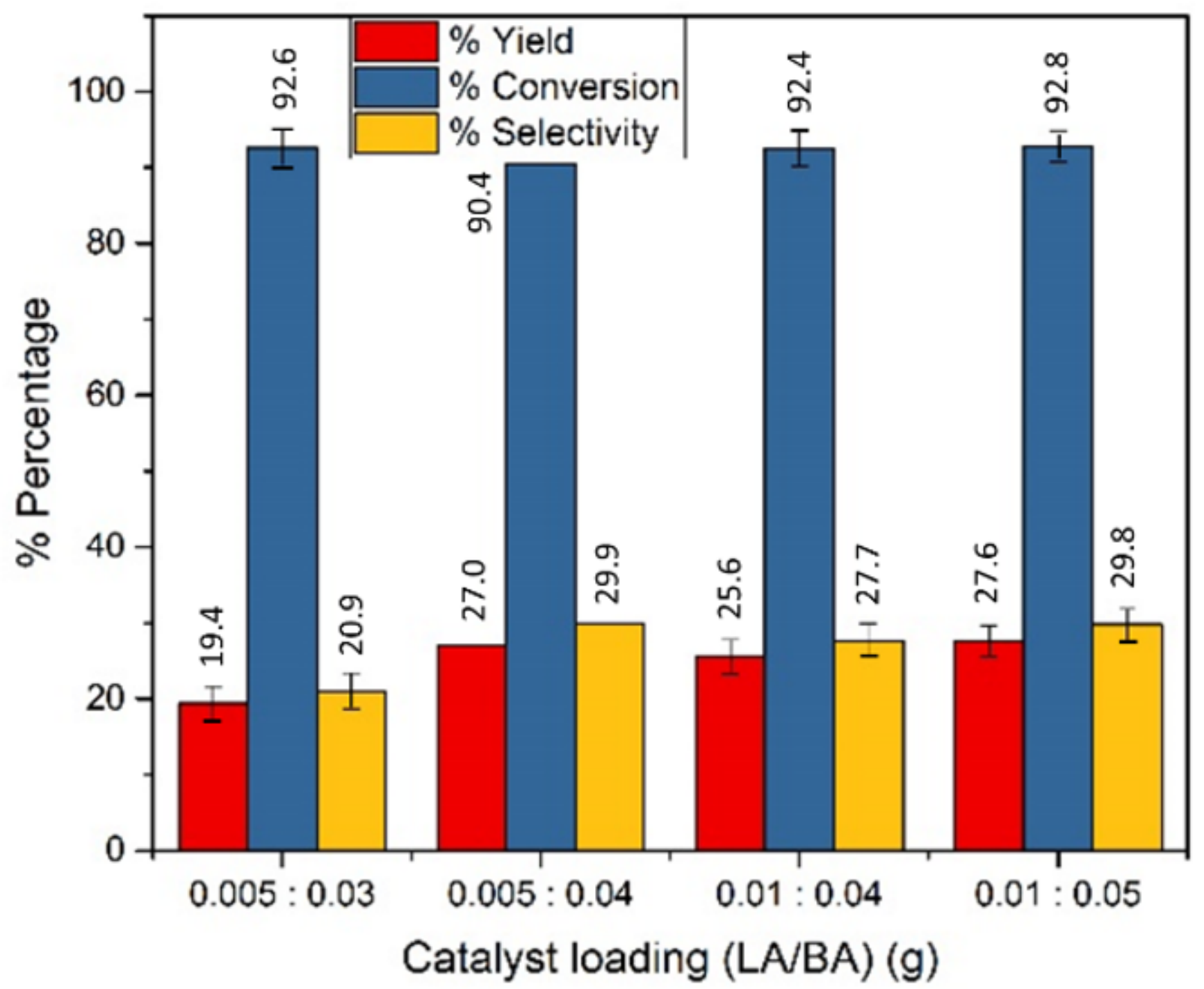

Figure 14

Effects of catalyst loading and the ratio of applied Lewis and BrØnsted solid acid catalysts (reaction conditions: $0.01 \mathrm{~g}$ glucose, $0.05 \mathrm{~g} \mathrm{NaCl}$, aqueous to organic phase volume ratio $=1: 3, \mathrm{NMP}: \mathrm{H} 2 \mathrm{O}$ volume ratio $=3: 1$, reaction temperature of $120^{\circ} \mathrm{C}$ and reaction time of $60 \mathrm{~min}$ ) 


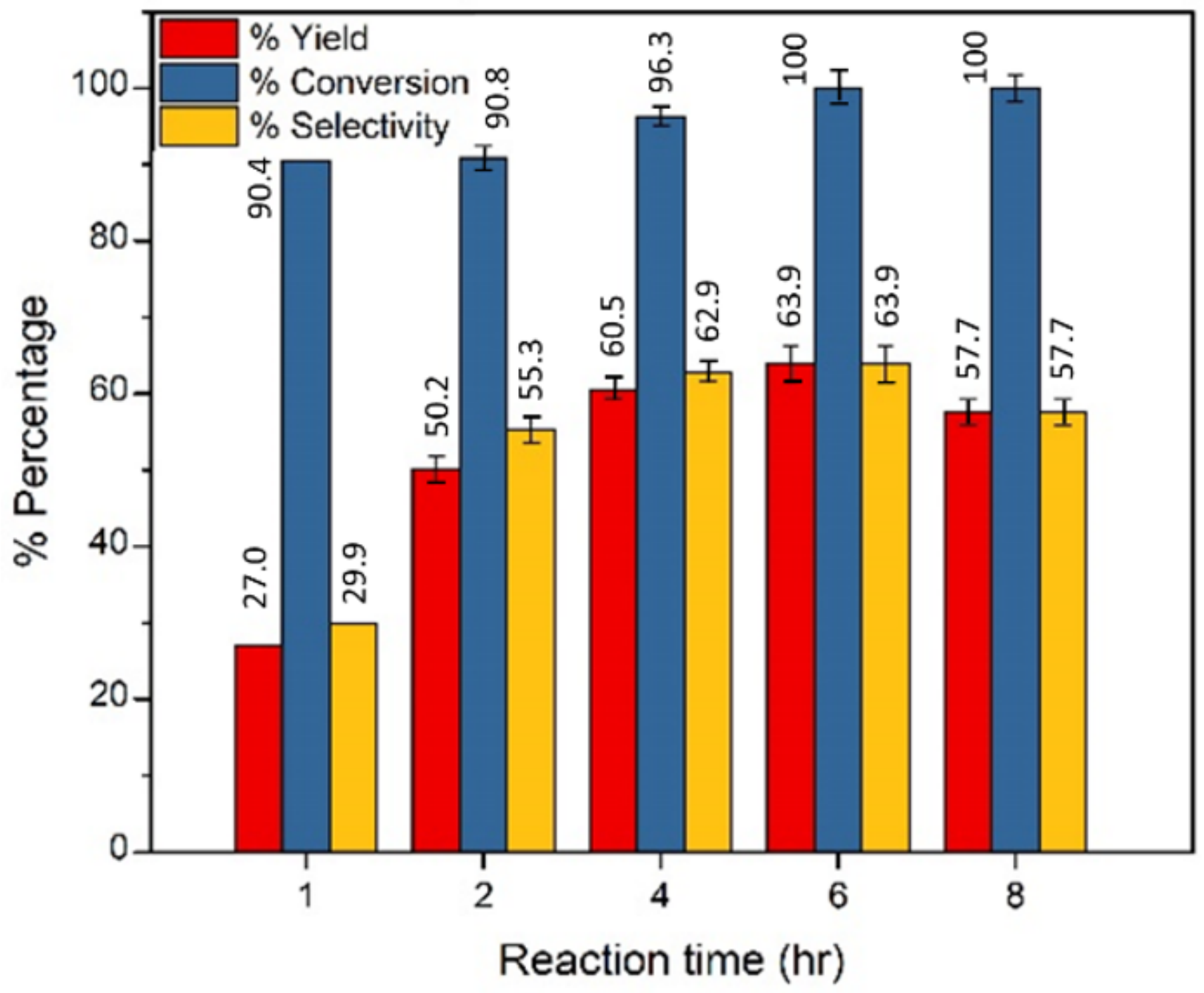

Figure 15

Effect of reaction time (reaction conditions: $0.01 \mathrm{~g}$ of glucose, aqueous to organic phase volume ratio = 1:3, NMP to $\mathrm{H} 20$ volume ratio $=3: 1,0.05 \mathrm{~g}$ of $\mathrm{NaCl}, 0.005 \mathrm{~g}$ of PC-Im4AILA, $0.04 \mathrm{~g}$ of PC-Im50BA, and reaction temperature of $120^{\circ} \mathrm{C}$ ) 


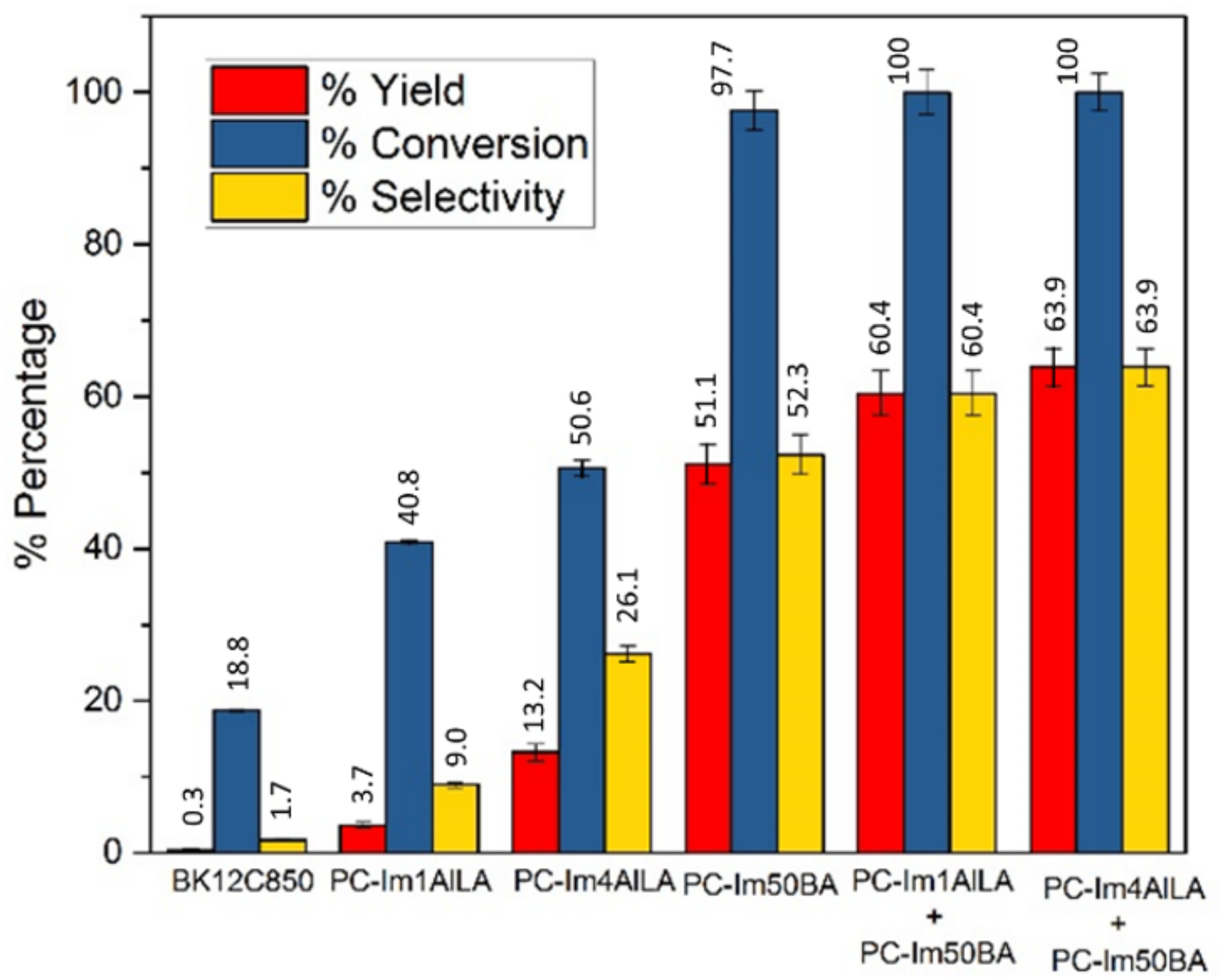

Figure 16

5-HMF production performance obtained by using various types of catalysts (reaction conditions: $0.01 \mathrm{~g}$ of glucose, aqueous to organic phase volume ratio $=1: 3, \mathrm{NMP}$ to $\mathrm{H} 2 \mathrm{O}$ volume ratio $=3: 1,0.05 \mathrm{~g}$ of NaCl , $0.005 \mathrm{~g}$ of PC-Im4AILA, $0.04 \mathrm{~g}$ of PC-Im50BA, reaction temperature of $120^{\circ} \mathrm{C}$, and reaction time of $6 \mathrm{~h}$ ) 
a)

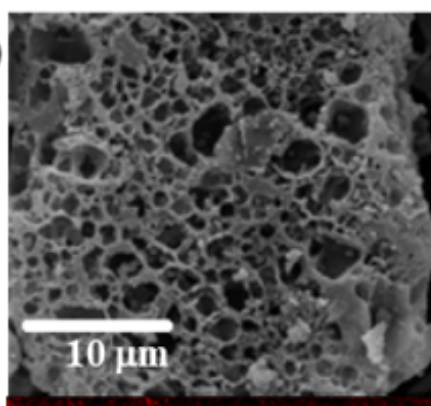

Al

o

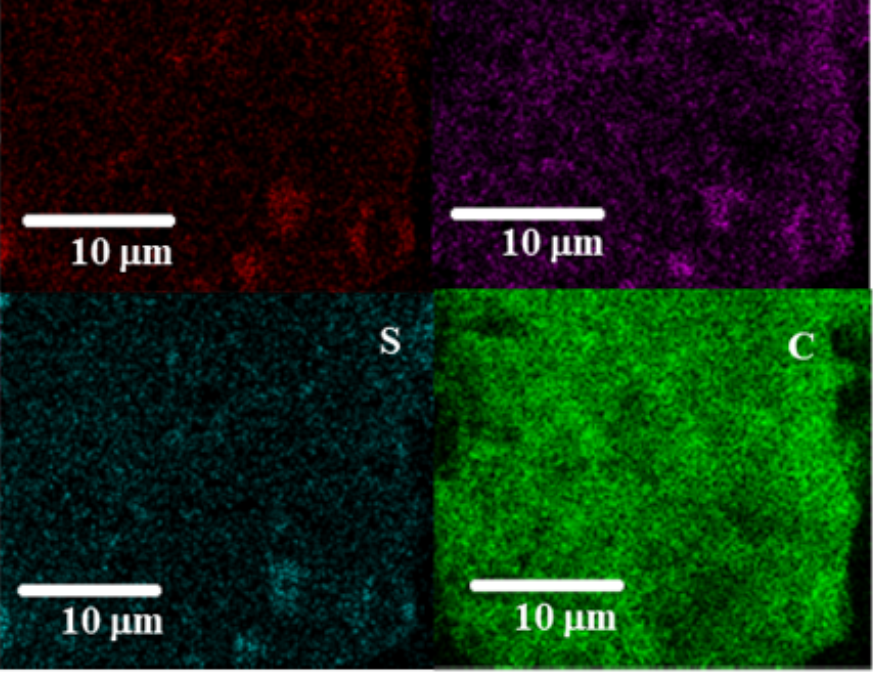

b)

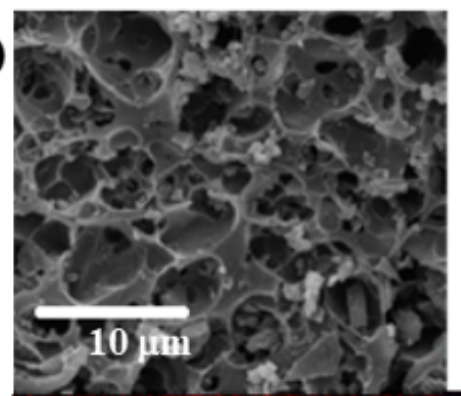

Al

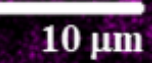

S

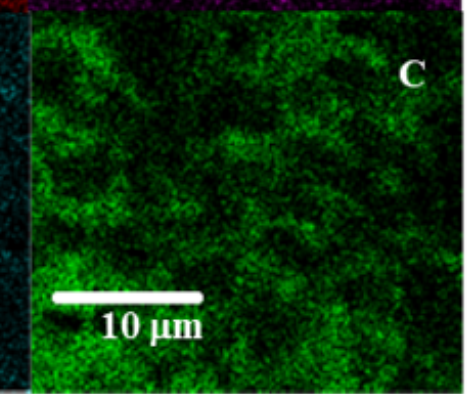

\section{Figure 17}

SEM images and the corresponding electron dispersive spectroscopic (EDS) mapping of the spent catalyst system (PC-Im4AILA + PC-Im50BA): a) 1st recycled, b) 3rd recycled 


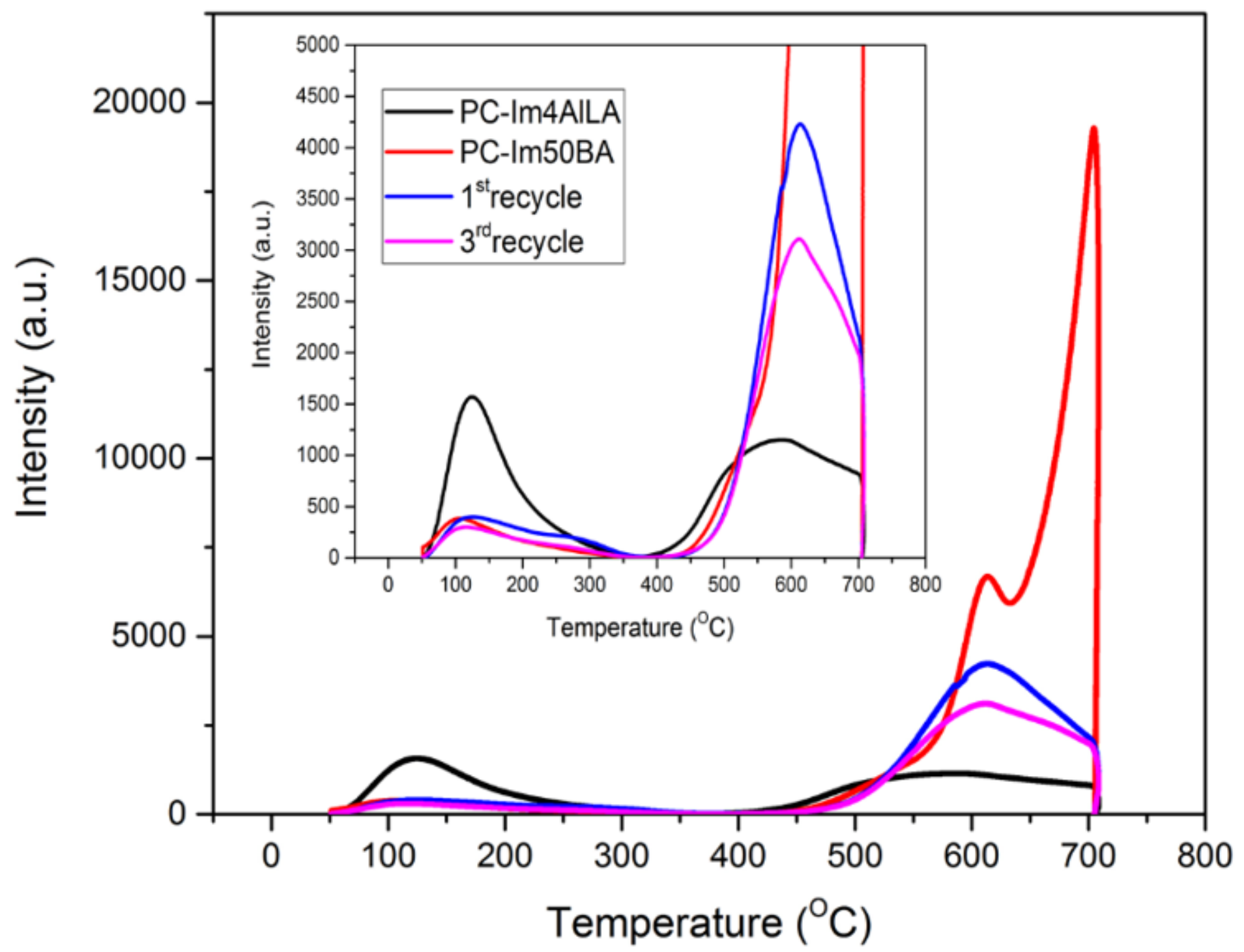

Figure 18

The comparison of NH3-TPD desorption isotherms between the spent catalyst systems (PC-Im4AILA + PC-Im50BA) and the fresh solid acid catalysts (PC-Im4AILA, and PC-Im50BA) analyzed by NH3-TPD 


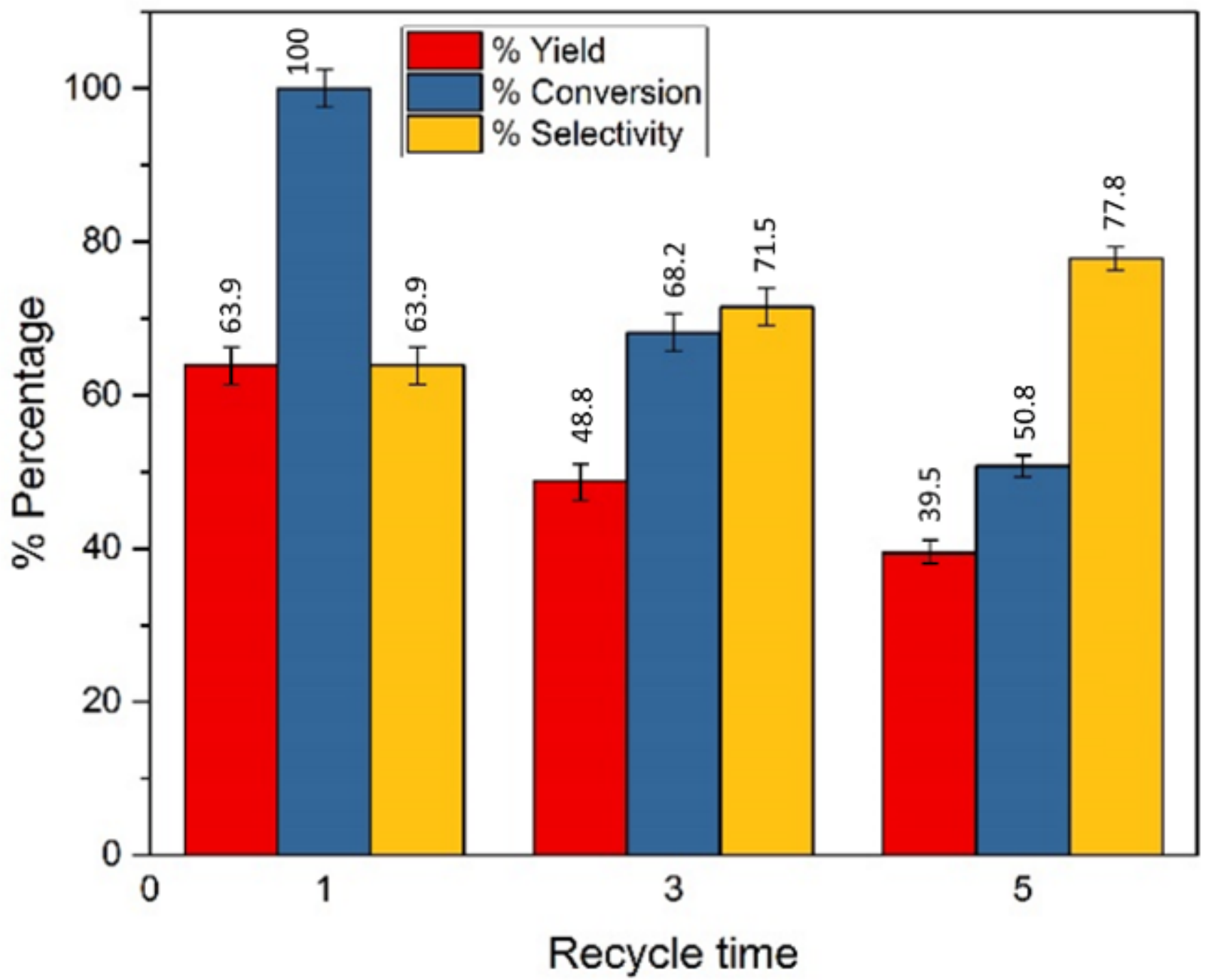

Figure 19

The catalyst recyclability (reaction conditions: $0.01 \mathrm{~g}$ of glucose, $0.05 \mathrm{~g}$ of $\mathrm{NaCl}$, catalyst ratio of 0.005:0.04 (PC-Im4AILA/PC-Im50BA), aqueous to organic phase volume ratio of 1:3, NMP to H2O of 3:1, reaction temperature of $120^{\circ} \mathrm{C}$, and reaction time of $6 \mathrm{~h}$ )

\section{Supplementary Files}

This is a list of supplementary files associated with this preprint. Click to download.

- GraphicalAbstract.png 